PNL-2685

UC-94b

\title{
Preliminary Stability Criteria for Compressed Air Energy Storage in Porous Media Reservoirs
}

\author{
J. A. Stottlemyre
}

June 1978

Prepared for the U.S. Department of Energy under Contract EY-76-C-06-1830

Pacific Northwest Laboratory Operated for the U.S. Department of Energy by

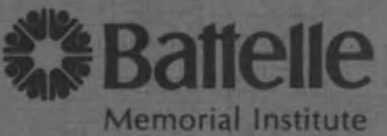


NOTICE

This report was prepared as an account of work sponsored by the United States Covernment. Neither the United States nor the Department of Energy, nor any of their empicyees, nor any of their contractors, subcontractors, or their employees, makes any wartanty, express or implied, or assumes any legal liability or responsibility for the accuracy, completeness or usetulness of any iniormation, apparatus, product or process disclosed, or represents that its use would not infringe privately owned rights.

The views, opinions and conclusions contained in this repont are those of the contractor and do not necessarily represent those of the United States Covernment or the United States Deparmant of Energy.

\author{
PACIFIC NORTHWEST LABORATORY \\ operated bv \\ BATTELLE \\ for the \\ UNITED STATES DEPARTMENT OF ENERGY \\ Under Contract EY-76-C-06-1830
}
Printed in the United States of America Available trom
National Technical Infornation Service
United States Department of Cammerce
5235 Port Royal Road
Springfield, Virginia 22151

Price: Printed Copy $s$ $\therefore$ Microfiche $\$ 3.00$

NTIS

-Pages Selling Price

$\begin{array}{ll}001-0.25 & \$ 4.60 \\ 025.050 & \$ 4.50 \\ 051-075 & \$ 5.25 \\ 076-100 & \$ 6.00 \\ 101-125 & \$ 6.50 \\ 126-150 & \$ 7.25 \\ 151-175 & \$ 8.00 \\ 175-200 & \$ 9.00 \\ 201-225 & \$ 9.25 \\ 226-250 & \$ 9.50 \\ 251-275 & \$ 10.75 \\ 276-300 & \$ 11.00\end{array}$


PNL-2685

UC-94b

33679000493470

PREL IMINARY STABILITY CRITERIA

FOR COMPRESSED AIR ENERGY STORAGE

IN POROUS MEDIA RESERVOIRS

J. A. Stottlemyre

June 1978

Prepared for

the U.S. Department of Energy

under Contract No. EY-76-C-06-1830

Pacific Northwest Laboratory

Richland, Washington 99352 


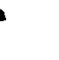

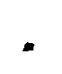

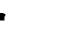




\section{SUMMARY}

This report summarizes results from the initial phase of study to establish subsurface design and operating criteria for a Compressed Air Energy Storage (CAES) facility. The primary objective was to derive a preliminary set of criteria that would help ensure the long term (30-40 year) integrity of CAES reservoirs in porous media, such as aquifers or abandoned natural gas reservoirs. In addition, appropriate research and development tasks were to be defined if the current technology was found to be inadequate.

Preliminary stability and design criteria for storage of compressed air in porous media were determined on the basis of a survey of the open literature and the experience of experts in industry and universities. The results were separated into two categories: criteria for low temperature air injection (under $200^{\circ} \mathrm{F} / 93^{\circ} \mathrm{C}$ ) and criteria for high temperature air injection (200 to $650^{\circ} \mathrm{F} / 93$ to $343^{\circ} \mathrm{C}$ ). Results are presented as maximum and/or minimum bounds for a number of parameters such as porosity, permeability, closure, storage pressure, caprock thickness, delta pressure, and caprock slope.

One of the prime conclusions derived from an evaluation of the low temperature concept is that the technology currently exists to handle the potential design and operating problems. Therefore, there appears to be no technical roadblocks to the successful demonstration of the CAES concept, and a pilot project could be constructed in the near future.

Many of the criteria established for low temperature air injection are equaliy applicable to the high temperature concept. However, a number of areas of uncertainty associated with the elevated temperature concept were identified. These included:

- the presence and impact of liquid phase water,

- the generation and transport of fine particulates,

- the thermo-mechanical stresses in the caprock, and

- the thermo-mechanical response of the well casing and cementation materials.

It was determined that these and other topics require additional study before the concept of using the air storage zone as a natural pebble bed for containment of the thermal energy of compression can be demonstrated as a viable alternative. 


\section{ACKINOWLEDGMENT}

The following individuals were consulted during the course of this study:

J. Apps, Lawrence Berkeley Laboratory

W. E. Brigham, Department of Petroleum Engineering, Stanford University

J. W. Fairchild, Manager of Gas Storage Division, INTERCOMP

D. L. Katz, Department of Chemical Engineering, University of Michigan

E. R. Lady, Mechanical Engineering Department, University of Michigan

C. G. Nelson, Northern Illinois Gas Company

H. J. Pincus, Department of Geological Sciences, University of Wisconsin, Mi iwaukee

H. J. Ramey, Jr., Department of Petroleum Engineering, Stanford University

W. H. Sommerton, Petroleum Engineering Laboratories, University of California at Berkeley

W. White, Materials Resource Laboratory, Pennsylvania State University

P. A. Witherspoon, Lawrence Berkeley Laboratory

Analytical studies were performed by G. C. Smith and L. E. Wiles of Pacific Northwest Laboratory (PNL).

Donald L. Katz deserves special commendation for his extensive assistance.

This study was an initial phase of the Reservoir Stability Program currently underway at PNL under the direction of W. V. Loscutoff. Funding and programmatic guidance is provided by George Chang of the Division of Energy Storage of the Department of Energy. 


\section{CONTENTS}

SUMMARY

ACKNOWLEDGMENT .

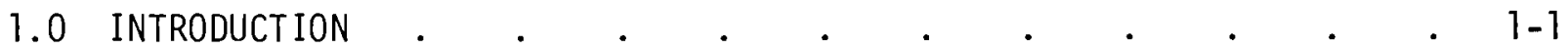

2.0 CONCLUSIONS AND RECOMMENDATIONS . . . . . . . . . . . . $2-1$

2.1 LOW TEMPERATURE AIR INJECTION •

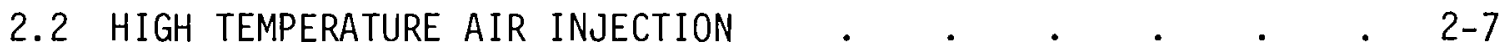

3.0 BACKGROUIND ON CAES TECHNOLOGY AND PRESENT AND

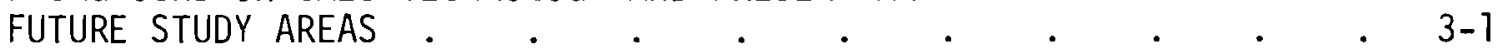

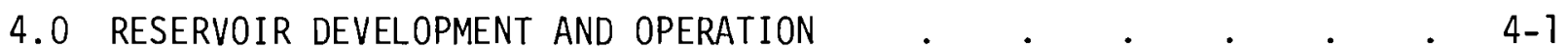

5.0 MAJOR POTENTIAL PROBLEM AREAS IN STORAGE OF
COMPRESSED AIR.
C. . . . . . . . . . . . . . . . . . . $5-1$

5.1 WELL CASING AND COMPLETION INTEGRITY $. \quad . \quad . \quad . \quad$. $5-1$

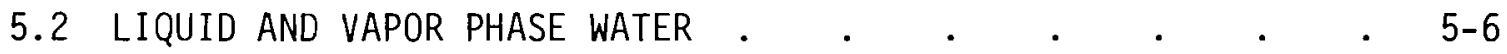

5.2.1 Sources of Liquid and Vapor Phases . . . . . 5-7

5.2.2 Air Storage Zone . . . . . . . . . 5-13

5.2.3 Consequences Associated with the Wetting

5.2.4 Dehydration Mechanism . . . . . . . 5-19

5.3 CAPROCK INTEGRITY . . . . . . . . . . . . $5-23$

5.4 GEOCHEMICAL REACTIONS . . . . . . . . . . . 5-28

5.4.1 Silicate and Carbonate Hydrolysis . . . . 5-29

5.4.2 Oxidation/Reduction Reactions . . . . . 5-30

5.4.3 General Corrosion and Scaling . . . . . . 5-31

5.4.4 Smectite (Clay) Swelling . . . . . . . 5-31

5.4.5 Residual Hydrocarbons . . . . . . . 5-33

5.5 PHYSICAL RESPONSE OF THE POROUS ROCK . . . . . . 5-34 REFERENCES

- Ref-1

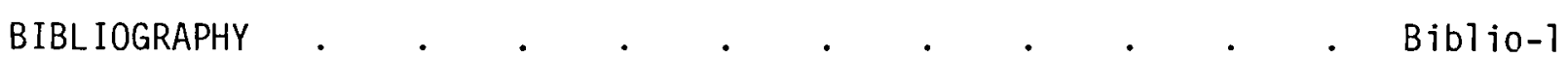




\section{FIGURES}

2-1 Saturation Pressure Versus Temperature for Water . . . . 2-9

3-1 Flow Diagram for Compressed Air Storage Plant . . . . . 3-1

3-2 Components of Underground Air Storage Flow System with Nomenclature . . . . . . . . . . . . . 3-2

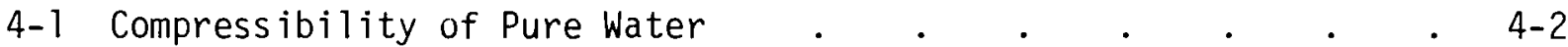

4-2 Conceptual Presentation of Various Zones Within a Multiwell Reservoir . . . . . . . . . . 4-4

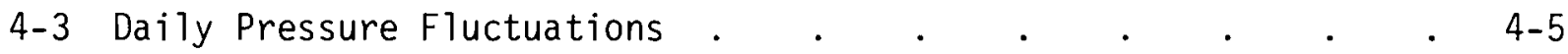

4-4 Radial Temperature Profile Based on a One-Dimensional Gas Flow Computer Simulation . . . . . . . . . . . 4-6

4-5 Temperature Cycling After One Year of Operation . . . . 4 4 4 4

5-1 Stress History of Casing During Steam or Hot Air Injection . . . . . . . . . . 5-3

5-2 Miscellaneous Capillary Pressure-Saturation Curves . . . 5-8

5-3 Permeability Versus Connate Water by Capillary Pressure . . 5-9

5-4 Comparison of Capillary-Pressure Results with Mercury and Air/Water . . . . . . . . . . 5-10

5-5 Relative Permeability for Consolidated and
Unconsolidated Sands . . . . . . . . . . . . . . . . $5-11$

5-6 Pore Space Saturation . . . . . . . . . . . . 5-11

5-7 A Heterogeneous Porous Mass Which Upon Drainage Retains Wetting Liquid in Region $P_{2}$. . . . . . . 5-12

5-8 Solubility of Water in Air at Various Temperatures
and Pressures. . . . . . . . . . . . . . . . 5-14

5-9 Thermal Conductivity of Kern River 0il Sands . . . . . 5-17

5-10 Thermal Conductivity of Partially Brine-Saturated
Quartz Sand . $.0 . \quad . \quad . \quad . \quad . \quad . \quad . ~ 5-17$

5-11 Conceptual Presentation of the Evaporation Process . . . . 5-20

5-12 Mechanism for Exposing the Caprock to Elevated Temperatures . . . . . . . . . . . 5-24

5-13 Measured and Computed Temperature-Depth Profile for Hot

5-14 Silica Solubility in Water . . . . . . . . . . 5-32 


\subsection{INTRODUCTION}

Compressed Air Energy Storage (CAES) appears to be an economically and technically viable method for energy storage. The surface facilities are conventional in nature and the natural gas storage industry supports over 50 years of subsurface storage experience. However, it was deemed necessary to explore how a reservoir might respond over a 20- to 40-year time frame to the somewhat unique temperature, pressure, and humidity characteristics associated with CAES.

Candidate reservoirs for the storage of compressed air include: 1) porous media such as sandstone aquifers or carbonate reefs, 2) solutioned salt cavities, and 3) hard rock caverns. Due to the relative number of interesting phenomena and the abundance of natural gas storage literature, the porous media alternative was initially addressed. An anticlinal (domed) sandstone aquifer system overlain by a shale caprock is presented as the base system for discussion purposes. Subsequent reports on the hard rock and salt alternatives will be available in FY-1978.

Any conclusions or recommendations contained in this report are based solely on the experience and judgement of the research team and on the available literature. It is envisioned that results from planned numerical, laboratory, and field investigations will significantly augment the information contained in this report.

The specific objectives of this initial phase of the study are:

- to specify, whenever possible, reservoir design and operating guidelines that will minimize the potential for unacceptable degradation of the wells, storage matrix, and containment strata, and

- to delineate areas of uncertainty and recommend appropriate analytical studies, laboratory experiments, and field investigations.

It is of primary interest to delineate any constraints on the design and operation of a CAES facility that might be imposed by the reservoir. In other words, it is important to specify maximum and/or minimum bounds for parameters such as injection temperatures, pore pressure fluctuations, 
or interstitial water contents. The remainder of this report is divided into the following areas:

- conclusions and recommendations

- background on the CAES concept

- reservoir development and operation, and

- major potential problem areas in aquifer storage. 


\subsection{CONCLUSIONS AND RECOMMENDATIONS}

This section is organized into two subsections: 1) conclusions and recommendations associated with low temperature air injection $\left(<200^{\circ} \mathrm{F} / 93^{\circ} \mathrm{C}\right)$, and 2) conclusions and recommendations associated with high temperature injection $\left(>200^{\circ} \mathrm{F} / 93^{\circ} \mathrm{C}\right)$. It is anticipated that the first CAES demonstration facility will operate in the low temperature regime with the heat of compression being removed from the air prior to injection into the storage reservoir.

The reasons for exploring the elevated temperature concept include: 1) a potential governmental ban on the use of premium fuels for the generation of electricity, 2) a potential escalation in premium fuel prices, 3) a potential minimum injection air temperature to expedite the dewatering of the critical (near-wellbore) zone, 4) a potential requirement to store air at elevated temperatures in coupled energy concepts such as solar - CAES, and 5) an increased cycle efficiency if inter and aftercoolers can be eliminated.

The distinction between the low and high temperature storage concepts should be kept in mind. Due to the added complexity associated with elevated temperatures, the majority of the discussion in this report is biased towards the advanced concept. The technical viability of this adiabatic cycle remains to be demonstrated via numerical, experimental, and field investigations. The low temperature storage concept, on the other hand, appears to be relatively straightforward. The possible exception is the necessity for near-wellbore dehydration and the potential for not being able to accomplish this with undersaturated low temperature air because of its relatively low vapor carrying capacity. If this problem can be negated, then the consensus of the research team is that the technology now exists to handle the pertinent engineering and/or operational problems, and that a full scale demonstration facility can be designed and constructed.

This conclusions section is designed to present a brief overview of the conclusions and recommendations from this initial study phase and as such is devoid of verbal and illustrative detail. 


\subsection{LOW TEMPERATURE AIR INJECTION}

This section includes the conclusions and recommendations associated with low temperature air injection $\left(<200^{\circ} \mathrm{F} / 93^{\circ} \mathrm{C}\right)$. Several preliminary design and stability criteria are summarized in Table 2-1.

The category of sandstone and carbonate reef aquifers spans a broad spectrum of possible storage configurations and media properties. The anticlinal sandstone aquifer will be considered the base case for this report. However, there is certainly potential for other structural and stratigraphic traps such as monoclines and terraces, fault bounded inclinal beds, domal structures associated with salt and igneous intrusives, lenses, up-dip wedges, etc. Futhermore, it is necessary to differentiate between sandstone aquifers and carbonate reef structures. The carbonate structures generally owe their porosity and high permeability to secondary solutioning processes and as such their extent is always highly suspect until proven by careful exploration. Vugular permeability tends to be strongly anisotropic and may exhibit preferential characteristics near the top of the structure only. In addition, the chemistry and mechanics associated with the carbonates is radically different to that of sandstones, especially at the higher temperatures and pressures. High permeability carbonate structures (i.e., Indiana limestones, etc.) are certainly viable candidates for a CAES facility and as such must be addressed in detail. However, for the purposes of this report, the reference case will be the anticlinal sandstone aquifer.

The storage matrix must exhibit adequate continuity of permeability to allow for interstitial water displacement. This is a function of the required air mass (plant size), the storage zone porosity, thickness and areal extent, formation anisotropy, and the presence or absence of natural barriers. Growth of the air bubble and the associated pressure, temperature, and volume characteristics depend on the ability to compress the sand and water constituents and ultimately displace the interstitial liquids ${ }^{(a)}$. If the matrix permeability

(a) Flushing of the matrix by the air will result in displacement of most of the interstitial water. However, up to $30 \%$ of the porosity may remain saturated. Water will reside in hydraulically isolated pockets, dead end pores, and pores that support a capillary retention force in excess of the air displacement pressure. This water will be considered the residual component of the interstitial liquid. 
TABLE 2-1. Preliminary Design and Stability Criteria For Low Temperature Injection

\begin{tabular}{|c|c|c|}
\hline Parameter & Maximum & Mininum \\
\hline Injection Temperature & $200^{\circ} \mathrm{F}\left(93^{\circ} \mathrm{C}\right)$ & $?$ \\
\hline Porosity & $N . A{ }^{(a)}$ & $10 \%$ \\
\hline Closure & N.A. & $150 \mathrm{ft}(46 \mathrm{~m})$ \\
\hline Centerpoint Thickness & N.A. & $30 \mathrm{ft}(9 \mathrm{~m})$ \\
\hline Permeability & N.A. & $300 \mathrm{md}$ \\
\hline Depth & $4000 \mathrm{ft}(1220 \mathrm{~m})$ & $600 \mathrm{ft}(183 \mathrm{~m})$ \\
\hline Mean Storage Pressure & $120 \operatorname{atm}(122 \text { bars })^{(b)}$ & 18 atm (19 bars) \\
\hline Maximum Charging Pressure & $218 \operatorname{atm}(221 \text { bars })^{(c)}$ & $33 \mathrm{~atm}$ (33 bars) \\
\hline Caprock Thickness & N.A. & $20 \mathrm{ft}(6 \mathrm{~m})$ \\
\hline Caprock Slope & $10-15$ degree & N.A. \\
\hline Delta Pressure ${ }^{(d)}$ & $1 / 2$ threshold & N.A. \\
\hline $\begin{array}{l}\text { Liquid Phase Water } \\
\text { Permissible in Critical } \\
\text { Zone }\end{array}$ & $0 \%$ & N.A. \\
\hline $\begin{array}{l}\text { Liquid Phase Water Per- } \\
\text { missible in Remainder of } \\
\text { Working Air Zone }\end{array}$ & Residual & N.A. \\
\hline \multicolumn{3}{|c|}{$\begin{array}{l}\text { (a) N.A. = not applicable } \\
\text { (b) Site specific, based on } 0.43-0.52 \mathrm{psi} / \mathrm{ft} \text { of depth. } \\
\text { (c) Site specific, based on } 0.8 \mathrm{psi} / \mathrm{ft} \text { of depth. } \\
\text { (d) Delta pressure = Maximum Charging Pressure less the discovery } \\
\text { hydrostatic pore pressure. }\end{array}$} \\
\hline
\end{tabular}


is bounded in some fashion, the water cannot be displaced, and in the absence of costly surface extraction of the liquid, the back pressure at the wellbore will tend to increase. Examples of such natural barriers are: pinchouts, low permeability shale layers, and certain types of faults. It should be emphasized that not all faults are barriers. If the fault offset results in complete sand/shale contact, then a barrier may be created. However, sand/sand contact can be an effective transmitter and shale/shale contact can be an adequate seal.

The porosity of the reservoir must support storage of the air within an acceptable volume. This general rule is dependent on the characteristics of the storage horizon (thickness, dip, etc.), the desired temperature and pressure characteristics of the air, and the monetary value of the associated surface acreage. Although not a fixed value, $10 \%$ porosity is recommended as a minimum.

For an anticlinal or domal structure, closure $>150 \mathrm{ft}(46 \mathrm{~m})$ ind centerpoint thickness $>30 \mathrm{ft}(9 \mathrm{~m})$ is desirable. Closure is defined as the vertical distance from the top of an anticline to the highest adjoining valley and represents the size of the container closed to normal horizontal movement. The axial thickness generally represents the storage zone thickness. The $30 \mathrm{ft}(9 \mathrm{~m})$ will allow for reasonable air bubble thickness and communication with a perforated casing. This criterion is conservative and should not be construed to mean that other potentially less desirable configurations cannot function as CAES reservoirs.

A permeability in excess of 300 millidarcys $\left(3.0 \times 10^{-13} \mathrm{~m}^{2}\right)$ is desired for the storage zone. Permeability appears to be one of the most important reservoir characteristics in determining the rate of water displacement and air deliverability. Although the lower limit on permeability will be determined by the economics of a given site, recent analytical efforts demonstrate that the work required to displace water or inject and extract air at reasonable rates increases dramatically for permeabilities below 300 millidarcys. 
The time integral of the storage pressure curve relative to the initial ambient aquifer discovery pressure must equal zero if a net bubble volume change is not desired. In other words, if the maximum pressure used in the reservoir or the kilogram-days in a week above the original aquifer pressure are not equal to the kilogram-days below, a gradual air bubble volume change will result. This condition cannot be changed suddenly by pressure manipulation because of the large difference in the viscosities of water and air.

Maximum charging pressure should not exceed $0.80 \mathrm{psi} / \mathrm{ft}$ of depth $(0.18 \mathrm{bars} / \mathrm{m})$. Lithostatic pressure is general1y $1.0 \mathrm{psi} / \mathrm{ft}$ of depth $(0.23 \mathrm{bars} / \mathrm{m})$. If the pore pressure exceeds the 1 ithostatic pressure, the overburden material will experience tensional stress. For most common rocks, tensile strength is much lower than compressive strength. As a result, fractures can develop. The natural gas industry has injected at $0.78 \mathrm{psi} / \mathrm{ft}$ of depth $(0.18 \mathrm{bars} / \mathrm{m})$ without perceptable problems.

The caprock should have a thickness in excess of $20 \mathrm{ft}(6 \mathrm{~m})$. This is to ensure spacial integrity and adequate surface area for cement bonding of the casing within the wellbore.

The caprock slope should be less than 10-15 degrees to minimize the potential for movement on pre-existing glide planes.

The caprock should have a threshold pressure greater than twice the maximum anticipated delta pressure (charging pressure above initial reservoir discovery level). Threshold pressure is essentially that gradient required to initiate water displacement within the caprock. The low permeability of a typical caprock is due to this high capillary retention force associated with high surface area to volume ratio (small diameter) pores. The pores remain fully saturated with water as long as the local differential air pressure does not exceed this threshold capillary retention level.

The residual water may occupy 10 to $30 \%$ of the available porosity. This water should not be ignored in the design and operation of a CAES facility. A porous media aquifer exhibits macroscopic heterogeneity and anisotropy. If air is injected into the matrix at a pressure in excess of the local interstitial fluid pressure (entry pressure), then the majority of the pore liquid 
will be displaced from the injection region and should no longer be of significant concern. However, in zones that 1) support only a single communications channel (throat) with the rest of the matrix, 2) support capillary retention forces in excess of the imposed air pressure gradient, or 3 ) are hydraulically isolated, the interstitial liquids will not be displaced by the advancing air front. This volume of groundwater is known as the reservoir residual liquid saturation. The potential consequences associated with the liquid phase, at least near the wells, include: 1) decreased air deliverability, 2) introduction of liquid and vapor phase water to the wells and surface facilities, 3) geochemical reactions, 4) increased apparent thermal diffusivity, and 5) reduction of effective air storage capacity.

Within the zone ideally defined by a radial distance $r_{c r i t}$ from a given wellbore, a state of total interstitial dehydration must be rapidly attained and continually maintained for the life of the project. The actual extent of this critical (near-wellbore) region has not as yet been quantified. Basically, it refers to the zone around the wellbore where "high velocity" airflow and elevated temperatures $\left(>212^{\circ} \mathrm{F}, 100^{\circ} \mathrm{C}\right)$ are observed. Preliminary estimates suggest a 15 to $50 \mathrm{ft}(5$ to $15 \mathrm{~m})$. Reservoir anisotropy, air injection temperatures and flow rates, and relative permeabilities will be important parameters in determining $r_{\text {crit }}$. It is anticipated that two-dimensional, multi-phase, anisothermal fluid flow computer models in conjunction with laboratory and field investigations will be required to adequately define the extent of this critical region and the time factors associated with the dehydration process. The predominant mechanism for dehydration appears to be the utilization of very dry air as the working fluid. It should be noted that the moisture carrying capacity of air increases dramatically with temperature.

Beyond the critical zone, the residual water content should not significantly affect the operation of the CAES facility. Therefore, interstitial dehydration of the remainder of the working air zone ${ }^{(a)}$ and the cushion air

(a) The working air zone will vary from site to site and is defined by the maximum radial distance that the mass of air cycled over a week will protrude into an ideal storage zone. This distance will possibly be 30 to $90 \mathrm{ft}$ ( 9 to $27 \mathrm{~m}$ ). 
zone should not be required. At the low airflow velocities expected in the regions away from the wells, the residual water will be essentially immobile in its liquid state. Furthermore, for temperatures of $200^{\circ} \mathrm{F}\left(93^{\circ} \mathrm{C}\right)$ or 1 ess, a totally saturated air mass is less than $1 \%$ water vapor. Since the flow field is ideally axially symmetric, a permeability reduction in a zone defined by a radial distance in excess of $r_{\text {crit }}$ should have negligible impact on air deliverability. In other words, the bottleneck is near the wellbore. Apparently the only adverse impact will be in the reduction of the effective air storage volume which may impact the required number of wells, the spacing, and the necessary surface acreage.

The temperature and degree of undersaturation of the injected air stream must be such that the net transport of water vapor is out of the reservoir. Drying of the injected air may have to be accomplished by cooling and subsequent reheating of the airstream since solid desiccants and refrigeration may be too expensive. Regardless of the method, the air must be sufficiently undersaturated to preclude condensation within the working air zone as a result of the decreasing radial temperature profile. Analytical and experimental studies will help quantify this criterion.

Safeguards are required to preclude accidental injection of humid air.

Subsurface anisotropy and heterogeneity must be ultimately evaluated. This would include analysis of initial wafering and the mechanism of crossflow communication among zones of preferential flow. In addition, the potential for channelized air spil1, water entrapment, and the existence of barriers to gravity drainage of condensate must also be evaluated.

\subsection{HIGH TEMPERATURE AIR INJECTION}

The following conclusions and recommendations are associated with high temperature air injection $\left(>200^{\circ} \mathrm{F} / 93^{\circ} \mathrm{C}\right)$.

Criteria for some parameters are temperature independent. They are:

- porosity, closure, centerpoint thickness, permeability, depth, mean storage pressure, maximum charging pressure, caprock thickness and slope, and threshold pressure. 
The injection air temperature ${ }^{(a)}$ should be such that:

1. completion cement is maintained at a temperature $\leq 650^{\circ} \mathrm{F}\left(343^{\circ} \mathrm{C}\right)$,

2. casing materials are maintained at a temperature $\leq 650^{\circ} \mathrm{F}\left(343^{\circ} \mathrm{C}\right)$, and

3. system is not exposed to temperatures that would initiate in-situ vaporization of interstitial liquids (Figure 2-1).

When developing the cushion air bubble, the first several cycles should be accomplished with low injection a ir temperatures $\left(150^{\circ} \mathrm{F} / 66^{\circ} \mathrm{C}\right)$. This is to ensure that displacement of the liquid phase water, above the residual level, has been accomplished within the working air zone.

Radial heat losses, as the air stream proceeds down the wellbore, must be minimized. This is to ensure that the cylindrical zone of caprock interfacing with the borehole is not exposed to elevated temperatures that may lead to its physical or chemical degradation. In other words, the thermal loading rate must be controlled. Before this criteria can be quantified, the response of saturated shale specimens to elevated temperatures should be evaluated experimentally.

The main areas of uncertainty associated with high temperature injection center around the wellbore and the working air zone and include the following:

1. the thermal/mechanical response of wellbore casing and cementation materials,

2. the presence and consequences of liquid phase water and high vapor pressures,

3. the potential for geochemical reactions,

4. the generation and transport of fine particulate matter, and

5. the integrity of the caprock.

These topics are dependent upon the interactions and characteristics of the rock constituents, free oxygen, water, and elevated temperatures.

(a) Additional maximum temperature restrictions may result from studies of thermal stresses in the caprock, geochemical reactions and reservoir anisotropy. 


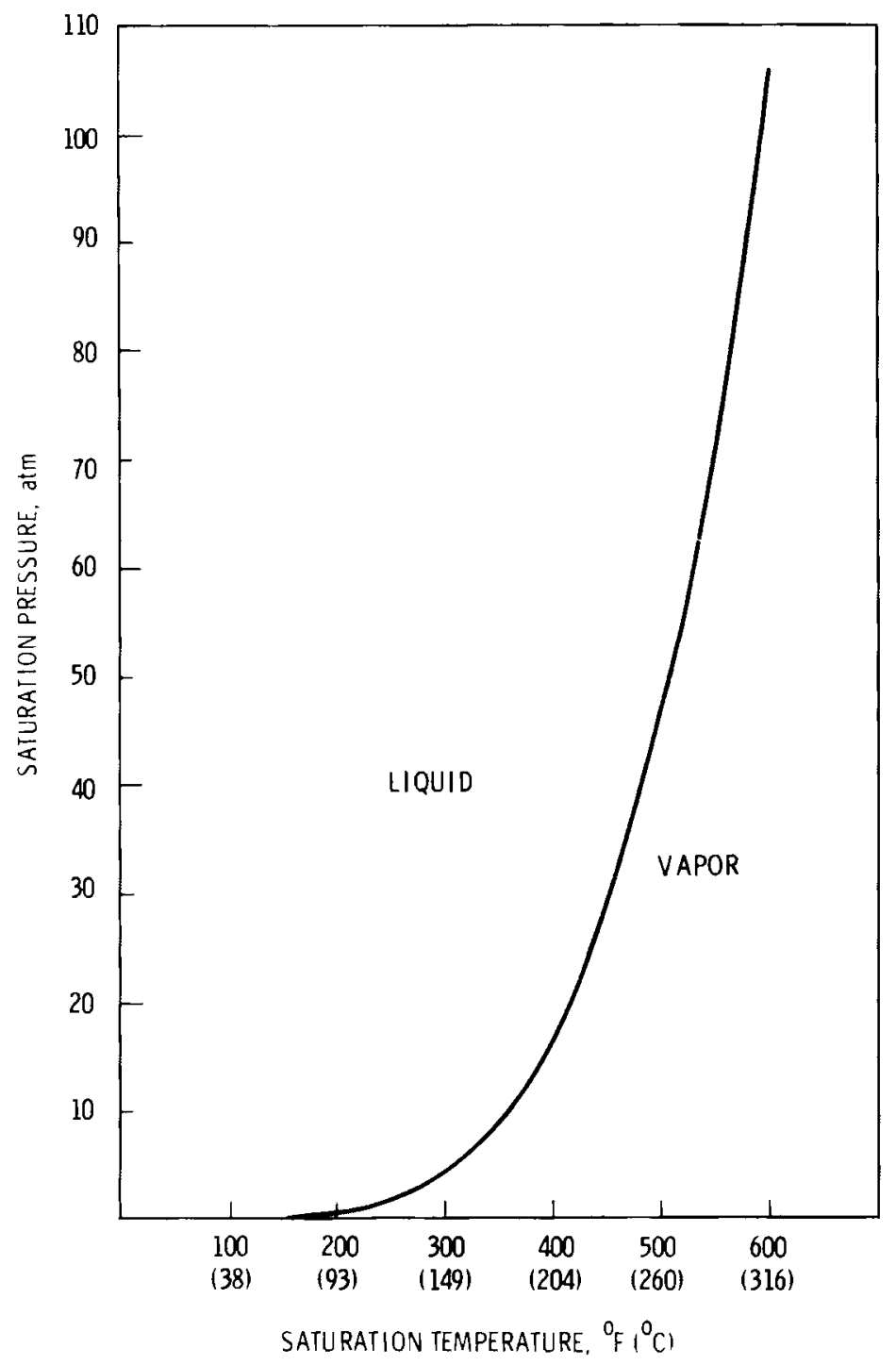

FIGURE 2-1. Saturation Pressure Versus Temperature for Water

Temperatures will decrease rapidly with distance from wellbore. Thermal energy associated with the injected air mass will be partitioned into:

1) vertical heat losses (5 to $10 \%), 2$ ) latent heat of vaporization of 1 iquid phase water, and 3) stored energy within the reservoir constituents. Thermal development of the reservoir will be slow and will depend in part on the amount of residual water present. 
The thermal energy lost from the air stream in transit down the borehole is thought to be relatively minor. However, vertical heat losses from the storage zone into the confining strata may be significant. Additional study is required to assess the potential heat transport mechanisms and energy flux associated with this vertical loss.

Additional study is required to determine how deep into the storage zone the well should be completed to prevent coning (water production) and enhanced heat losses.

Drying of the near-wellbore region is critical. The process of dehydration with undersaturated air may dictate a minimum temperature criterion based on the vapor carrying capacity of air as a function of temperature. Analytical and experimental studies will help characterize this process.

The thermal energy will be stored in the solid rock constituents in the vicinity of the borehole. Additional study is required to establish realistic temperature profiles. The total volumetric heat capacity of the rock matrix is much greater than that of the air, and it is expected that the air, water, and rock constituents will attain thermal equilibrium very quickly. This will dictate rapid attenuation of the temperature with radial distance from the borehole. If liquid phase water is present, temperature profiles will tend to flatten somewhat due to liquid and vapor transport of thermal energy and higher thermal conductivity. If solid/solid conduction and gaseous diffusion are the only working mechanisms, the thermal development will be very slow.

Given the uncertainties associated with the temperature, pressure, and humidity characteristics associated with high temperature storage, it is recommended that pertinent hydrolytic and oxidation/reduction reactions be experimentally investigated with respect to the storage matrix and caprock constituents.

The potential for differential thermal expansion and/or microfracturing of mineral grains and cementation material leading to fine particle production should be investigated in a laboratory experimental program. 
The potential for physical and chemical degradation of the cylindrical caprock zone interfacing with the wellbore cannot presently be dismissed. Radial heat losses from the air stream and short range conduction may expose this material to elevated temperatures. Therefore, any experimental program should address the high temperature response of shale and other caprock materials.

At the lateral interface between the storage horizon and the caprock, shale or anhydrite material may experience physical and chemical degradation over a vertical span of one or two meters. Given the high permeability contrast between the storage zone and the caprock zone, the air mass will tend to flow totally within the storage zone. Thus, no advective heat transport mechanism should be active in the caprock. Conduction and gaseous diffusion appear to be the only heat and mass transfer mechanisms associated with an intact caprock. Similarly, any adverse oxidation products generated within this 3- to 5-ft ( $1-$ to $2-\mathrm{m}$ ) caprock zone must rely on gaseous diffusion in response to a concentration gradient to proceed towards the borehole. Furthermore, these gaseous oxidation products will buffer the overlying material from further oxidation reactions.

Differential thermal expansion between the storage zone and the caprock may result in unacceptable stresses. Numerical modeling efforts will assess this potential problem.

Field testing at elevated temperatures should be conducted in conjunction with the proposed DOE-EPRI demonstration facility designed for low temperature air. Results from a few high temperature wells at the periphery of the cushion air bubble would be more advantageous than a separate small scale test facility since the large cushion air bubble would already be developed. The time scale of the project may be some concern, however. 


\subsection{BACKGROUND ON CAES TECHNOLOGY AND PRESENT AND FUTURE STUDY AREAS}

The objectives of this section are: 1) to familiarize the reader with porous, permeable media as potential air storage reservoirs, 2) to introduce a number of subject areas that were addressed in this study, and 3) to delineate those areas requiring additional study.

Figures 3-1 and 3-2 give a schematic representation of a hypothetical CAES project with aquifer storage. Current designs are based on low temperature

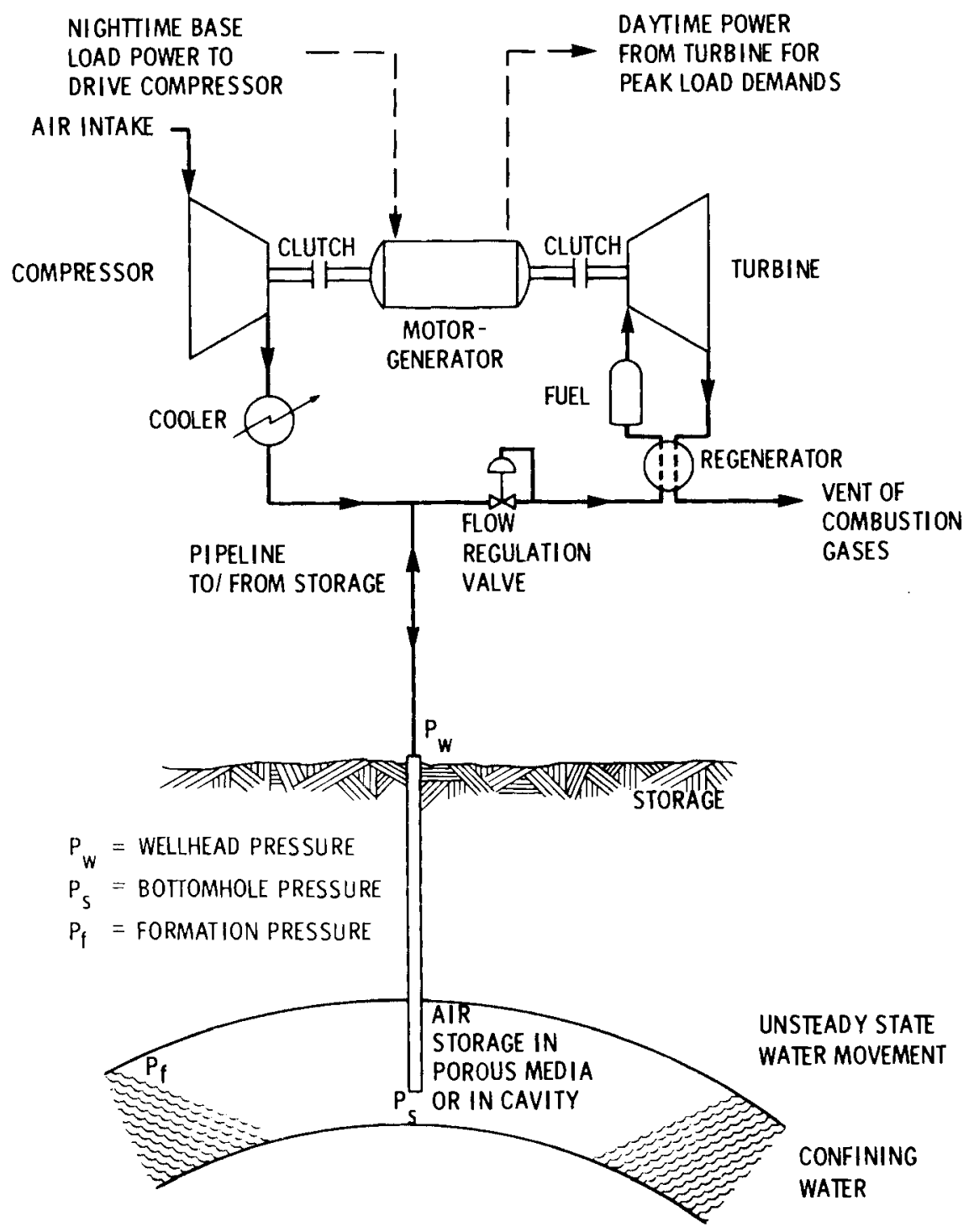

FIGURE 3-1. Flow Diagram for Compressed Air Storage Plant (1) 


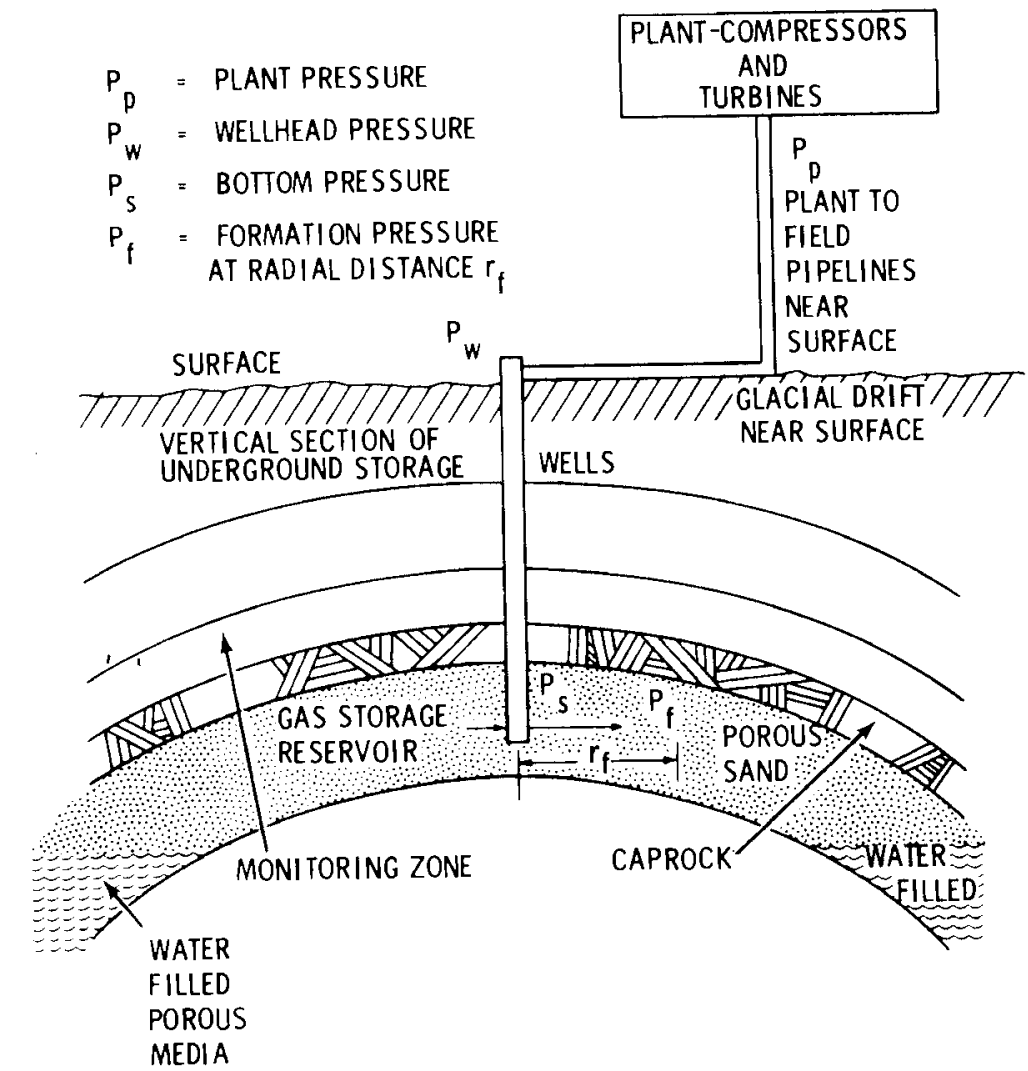

FIGURE 3-2. Components of Underground Air Storage Flow System with Nomenclature( 1 )

$\left(200^{\circ} \mathrm{F} / 93^{\circ} \mathrm{C}\right)$ air injection. One of the primary. conclusions of the workshop conducted as part of this study is that the technology now exists to handle the pertinent engineering and/or operational problems, and a full scale demonstration plant could be designed and constructed in the near future. The only significant question remaining concerns the near-well drying problem. Low temperature air may not have adequate vapor transport capacity to remove the residual water in an expedient manner.

Storage of the thermal energy of compression by injecting the air into the storage horizon at elevated temperatures $\left(200\right.$ to $650^{\circ} \mathrm{F} / 93$ to $\left.343^{\circ} \mathrm{C}\right)$ is also being investigated. Some additional uncertainty resides with this high temperature concept. Specifically, this includes: 1) wellbore and reservoir engineering and operation, 2) thermodynamic cycle efficiencies and the usability of low quality energy, 3) surface facilities design and reliability, and 4) overall economics. 
This study is restricted to wellbore and reservoir engineering and operational aspects of the overall concept. The list of topics addressed in this study is presented in Table 3-1. Those requiring further study are delineated in Table 3-2. It must be emphasized that most of the topics in Table 3-2 are oriented towards elevated temperature storage since this concept has the most unknowns. No attempt has been made to prioritize the list at this time. Section 5.0, however, will expand on the five areas considered most important.

Section 4.0 is a brief discussion of reservoir development and operation and Section 5.0 is a detailed presentation of the following topics: 1) well casing and completion cement integrity, 2) liquid and vapor phase water, 3) caprock integrity, 4) geochemical reactions, and 5) physical response of the porous rock. 


\section{TABLE 3-1. Subjects Addressed During the Study}

I. Temperature Effects

A. Casing and grouting response to elevated and cyclical temperatıres and associated gradients

1. therma i expansion and fatigue

2. cement dehydration

B. Reduced capillary forces in the caprock and subsequent migration of the wetting-nonwetting phase interface

C. Vaporization of liquid phase water within the nearwellbore zone and subsequent mass and heat transfer mechanisms

D. The temperature profile within the storage matrix as a function of time

E. Condensation of injected water vapor

F. Temperature dependence of geochemical reactions and product transport

1. the space-time association of elevated temperatures and liquid phase water

2. chloride stress corrosion and silica and calcite scaling

3. hydrolytic and redox reactions

G. The potential for and temperature dependence of inelastic pore and vug deformation

$H$. Fracturing and/or buckling of the caprock due to differential thermal expansion

I. Decreases in air deliverability with elevated temperatures (viscosity effects)

J. Residual hydrocarbon oxidation at elevated temperatures

$k$. Radial and vertical heat losses

$L$. Thermal cycling and attenuation with time

M. Heat storage in the rock constituents (axially symmetric case)

N. Increase in cushion air volume and/or pressure with elevated temperature

0 . Thermal expansion of grains into pore interstices

P. Degradation of grains and cementation and associated particulate production
II. Effective Stress Effects

A. Caprock threshold pressures and the maximum allowable delta pressure (pressure above discovery hydrostatic) during a cycle

B. Pressure manipulations during and subsequent to cushion bubble growth and the impact of flow resistance

c. Potential for tensional stresses from high injection pressures

D. Matrix fatigue from pore pressure cycling

E. Pore deformation resulting from a rapid reduction in pore pressure

F. Pressure solutioning

G. Movement along high angle glide planes in the caprock

H. Communication among preferential flow zones (wafering and channeling.

I. Relative permeabilities

J. Air/water/rock compressibility

III. Liquid and Vapor Phase Water Effects

A. Impact on air oeliverability (permeability decrease, water migration, factor increase

B. Impact on surface facilities

C. Weakening of rock constituents (hydrolytic weakening)

D. Geochemical reactions and smectite migration and swelling

E. Apparent thermal diffusivity characteristics

F. Vaporization and transport of residual water in the near well region.

IV. General Effects

A. Formation anisotropy and heterogeneity

B. Loss of surface facilities such as dehydration

C. Air storage and deliverability as a function of permeability, porosity, viscosity, and wellbore size

D. Types of reservoir and caprock material 


\section{TABLE 3-2. Areas Requiring Further Investigation(a)}

I. The Critical (near-well) Zone and the Remainder of the Working Air Zone

A. The humidity problem

1. minimum degree of undersaturation and minimum temperature required for the injected air mass

2. size of the critical zone

3. time to dehydrate the critical zone and ability to maintain it free of liquid phase water for the project duration

4. consequences assuciated with liquid phase water

a. air deliverability

b. geochemical reactions

c. accumulation of water in the well bottom and/or transport to surface facilities

d. thermal diffusivities

B. Well casing and grouting response to elevated and time varying temperatures

1. stress-strain response of the casing

2. cement failure due to thermal stress, fatigue, or dehydration

c. Rock degradation

1. geochemical reactions

2. particulate matter generation and production
D. Heat losses

1. radial losses from descending air stream

2. vertical losses from the storage zone

II. Caprock

A. Physical and chemical decomposition

1. dehydration and loss of containment capacity

2. geochemical reactions and product migration

3. movement on high angle glide planes

4. differential thermal expansion

B. Mass and heat transfer

1. convection/conduction/diffusion (relative magnitudes)

2. vertical heat losses

c. Inhomogeneity

III. Cushion Bubble Zone

A. Temperature, pressure, and saturation profiles

1. time variance

2. impact on potential geochemical reactions and mechanical stability

B. Optimal conditions for cushion bubble development

C. Formation anisotropy and heterogeneity and the potential for wafering and channel losses

(a) Refer to "Presentation of Specific Topics" for further discussion on what are considered to be the five most important problem areas. 


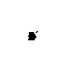

.

-

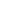




\subsection{RESERVOIR DEVELOPMENT AND OPERATION}

Some of the required characteristics of an underground storage zone are:

1. a zone of reasonable porosity exceeding $30 \mathrm{ft}(9 \mathrm{~m})$ in thickness and having a permeability in excess of 300 millidarcys $\left(3.0 \times 10^{-13} \mathrm{~m}^{2}\right)$,

2. a closure in excess of $150 \mathrm{ft}(46 \mathrm{~m})$,

3. sufficient areal extent, thickness, and depth to permit the desired air storage volumes and pressures, and

4. a caprock with sufficiently high threshold pressure characteristics and a thickness in excess of $20 \mathrm{ft}(6 \mathrm{~m})$.

To develop an air storage bubble within such an aquifer, air is injected at pressures exceeding local hydrostatic pore pressure $(0.43$ to $0.52 \mathrm{psi} / \mathrm{ft})$. The water and sand matrix is compressed by this advancing air front. The constituent densities increase as a function of the injection temperature and pressure and their respective compressibilities (Figure 4-1). As can be seen from the figure, water has a very low compressibility. However, since the term aquifer implies a reasonable continuity of the water storage zone, the total volume of water compressed even slightly is very large.

The pressure wave associated with air injection moves radially outward. Actual displacement of interstitial water lags this pressure front but eventually liquid phase water above the residual level is expelled by the advancing air mass. In general, the mass of water, not displaced during this development of the cushion air bubble, may occupy up to $30 \%$ of the available pore volume. It has a preference for the smaller pores where the surface area to volume ratio is maximized. In other words, this residual liquid phase is contained in pores that support a high capillary retention pressure relative to the air injection pressure. Furthermore, some liquid phase water may be trapped in dead end pores and hydraulically isolated pockets.

As long as the charging air pressure exceeds the ambient aquifer hydrostatic pressure the air bubble will expand and water will continue to be displaced. Conversely, if the injection pressure is decreased to a level below the water drive head, the bubble will ultimately respond with a volume reduction. 


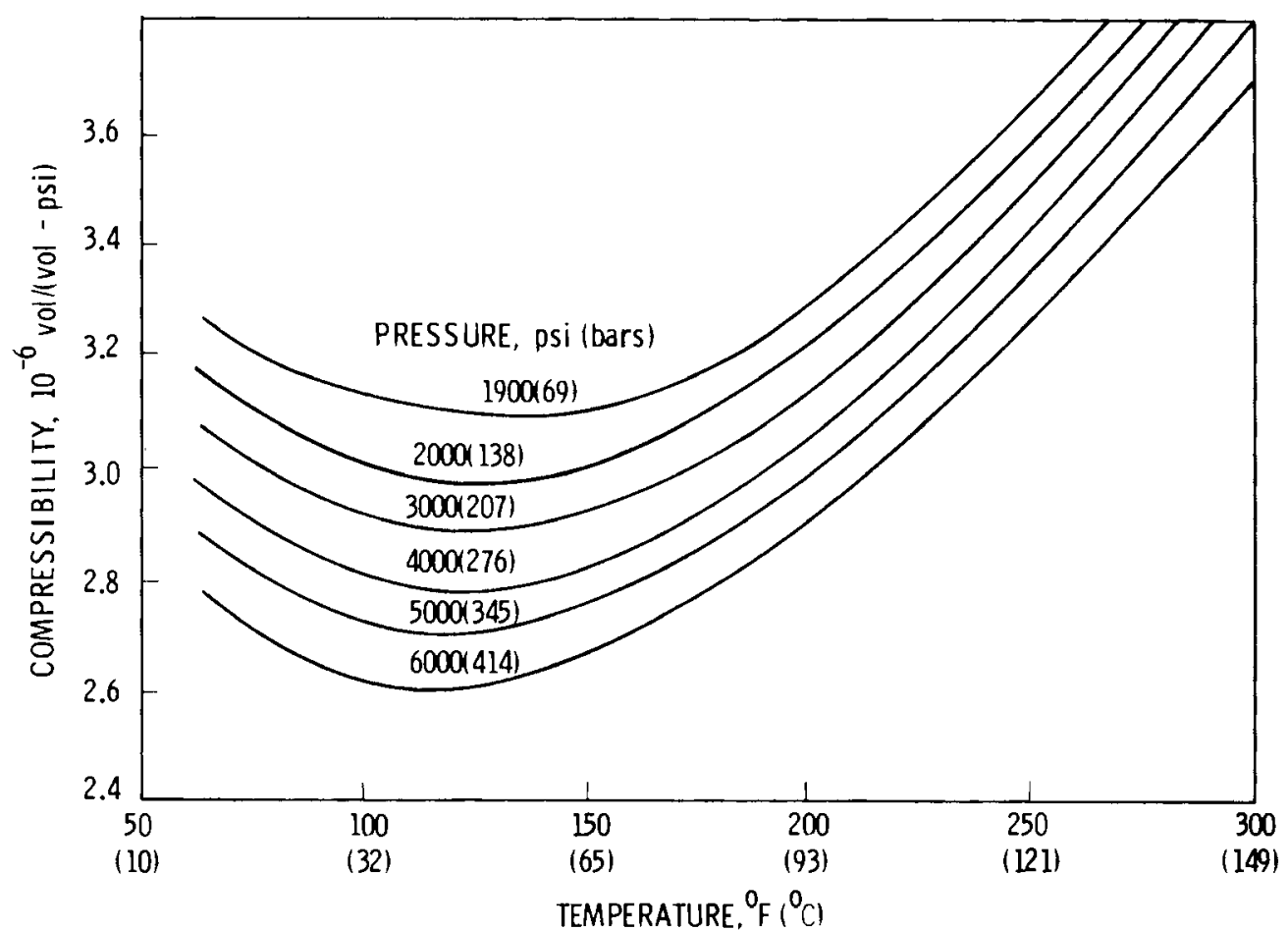

FIGURE 4-1. Compressibility of Pure Water (1)

Development of this cushion or base air bubble will typically require a period of 2 to 4 years. Further enlargements may be accomplished over the first 10 years of operation. In general, the total quantity of cushion air required to support a $600 \mathrm{MW}$ facility will be on the order of $1.5 \times 10^{9} 1 \mathrm{~b}_{\mathrm{m}}$ $\left(0.68 \times 10^{9} \mathrm{~kg}\right)$. For comparison purposes, Table 4-1 presents approximate project design parameters for four different porous media reservoirs.

The initial several cycles of the cushion air bubble development should be accomplished at temperatures below about $150^{\circ} \mathrm{F}\left(66^{\circ} \mathrm{C}\right)$. A general rule is that liquid phase water above the residual level must be removed from the zone that will ultimately contain the working (weekly cycle) air mass prior to the introduction of high temperature air. Furthermore, the inner critical zone associated with high velocity airflow must be totally dehydrated and perpetually maintained in that state (Figure 4-2). Motivation for this stipulation will be discussed subsequently. The size of the working air zone will 
TABLE 4-1. Comparison of Preliminary Project Designs or Reservoirs (1)

\begin{tabular}{|c|c|c|c|c|}
\hline Design Parameters & $\begin{array}{c}\text { Belle River } \\
\text { Mills } \\
\end{array}$ & $\begin{array}{l}\text { Herscher } \\
\text { Galesville }\end{array}$ & $\begin{array}{l}\text { Brookville } \\
\text { Galesville }\end{array}$ & Media \\
\hline Type of Reservoir & reef & aquifer & aquifer & aquifer \\
\hline Depth, ft & 2150 & 1780 & 780 & 2150 \\
\hline Natural Pressure, psi & 1132 & 715 & 240 & 840 \\
\hline $\begin{array}{l}\text { Surface Acres } \\
\% \text { Porosity } \\
\text { md Permeability }\end{array}$ & $\begin{array}{l}1400 \\
10 \\
320\end{array}$ & $\begin{array}{c}2800 \\
19 \\
400-3000\end{array}$ & $\begin{array}{c}3700 \\
18 \\
400-600\end{array}$ & $\begin{array}{r}5000 \\
17.2 \\
488\end{array}$ \\
\hline $\begin{array}{l}\text { MW Power } \\
\mathrm{hr} / \text { week }\end{array}$ & $\begin{array}{l}600 \\
50\end{array}$ & $\begin{array}{l}600 \\
50\end{array}$ & $\begin{array}{l}600 \\
50\end{array}$ & $\begin{array}{c}600+ \\
50\end{array}$ \\
\hline Airflow, MMcf/hr & 100 & 100 & 135 & 100 \\
\hline Turbine Air, psi & 588 & 588 & 147 & 730 \\
\hline Reservoir Pressure Range, psi & $693-760$ & $651-722$ & $217-263$ & $818-862$ \\
\hline Maximum Weekly Air Stored, Bcf & 2.15 & 2.15 & 2.9 & 2.15 \\
\hline Base Air Used, Bcf & 22.3 & 20 & 13.5 & 34 \\
\hline Number of $1 / \mathrm{W}$ Wells & 100 & 253 & 539 & 100 \\
\hline $\begin{array}{l}\text { Estimated Cost of Storage Project, } \\
\qquad M \\
\$ / k W\end{array}$ & $\begin{array}{l}25 \\
41\end{array}$ & $\begin{array}{l}38 \\
63\end{array}$ & $\begin{array}{l}40 \\
67\end{array}$ & $\begin{array}{l}35 \\
60\end{array}$ \\
\hline
\end{tabular}



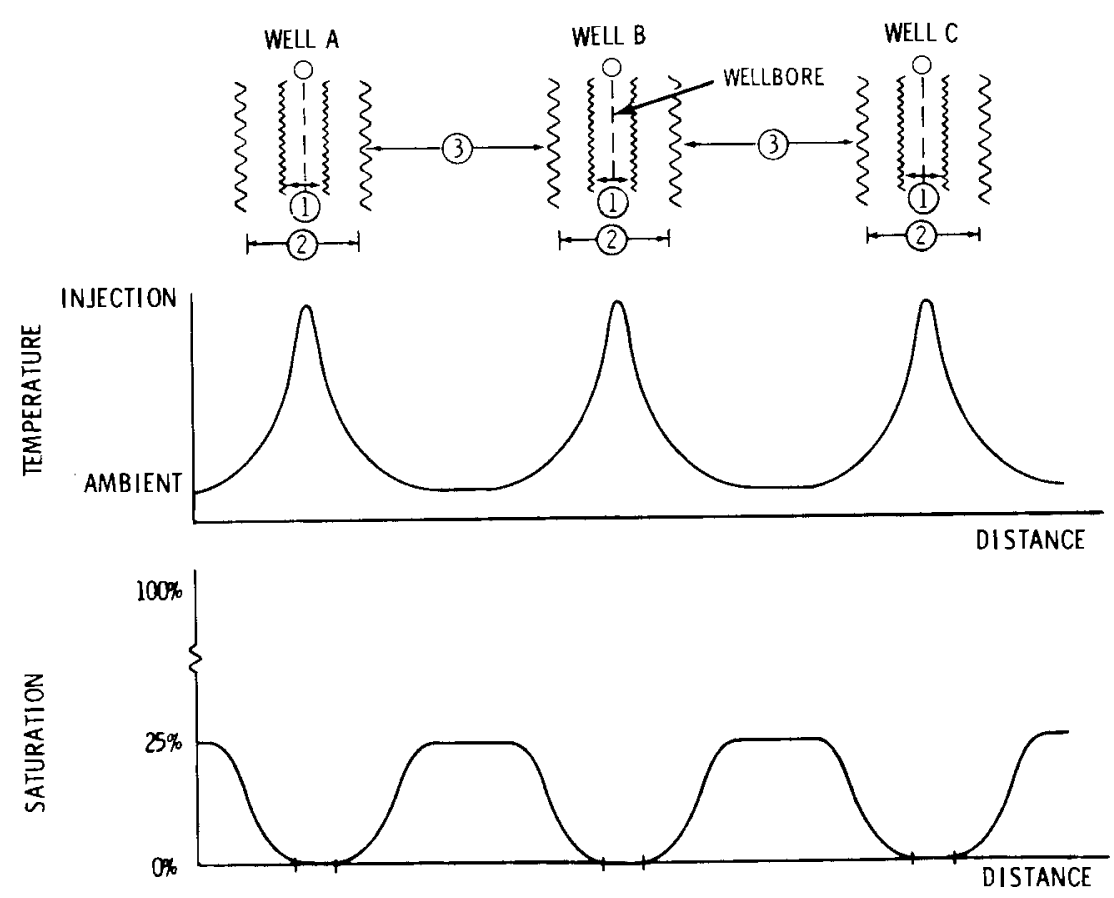

ZONE (1) CRITICAL ZONE

ZONE(2) WORKING AIR ZONE

ZONE(3) CUSHION AIR ZONE

FIGURE 4-2. Conceptual Presentation of Various Zones Within a Multiwell Reservoir

depend on the specific project design, however it may have a radial extent of 30 to $90 \mathrm{ft}(9$ to $27 \mathrm{~m})$ from the borehole. Similarly, the critical zone may be on the order of 15 to $50 \mathrm{ft}(5$ to $15 \mathrm{~m})$.

After the cushion air bubble is of sufficient size to support weekly plant operation, the working air mass will be injected and withdrawn in the cyclical nature depicted in Figure 4-3. A one-dimensional (gas/solid) computer model was developed to lend perspective to the problem. Simulation of this weekly mass flow cycle and the associated temperature cycling over a period of one year was conducted. The following conditions were used:

- reservoir ambient temperature $100^{\circ} \mathrm{F}\left(38^{\circ} \mathrm{C}\right)$

- charging temperature $450^{\circ} \mathrm{F}\left(232^{\circ} \mathrm{C}\right)$ 


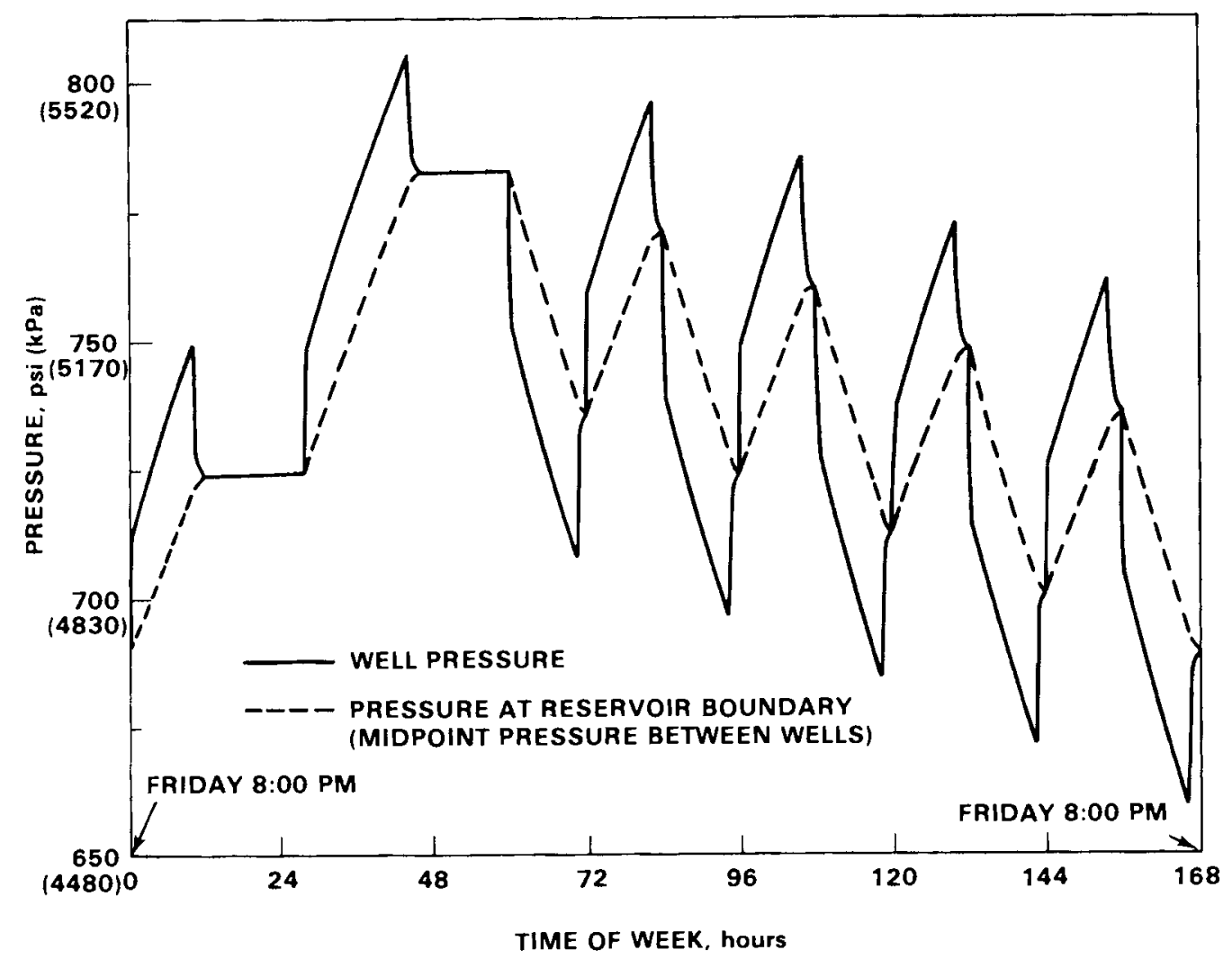

FIGURE 4-3. Daily Pressure Fluctuations

- initial ambient reservoir pressure 735 psi (50 bars)

- charging mass flow rate

- storage zone permeability

$427 \mathrm{lbm} / \mathrm{hr}-\mathrm{ft}(634 \mathrm{~kg} / \mathrm{hr}-\mathrm{m})$

- storage zone porosity

500 millidarcys $\left(500 \times 10^{-15} \mathrm{~m}^{2}\right)$

- rock and air thermal conductivity $1.0 \mathrm{Btu} / \mathrm{hr}-\mathrm{ft}-{ }^{\circ} \mathrm{F}\left(1.56 \times 10^{5} \mathrm{~W} / \mathrm{m}-{ }^{\circ} \mathrm{C}\right)$.

It was assumed that the storage zone was totally free of water and that the rock constituents and the air mass attained thermal equilibrium instantaneously.

The most apparent results are: 1) the temperature profile attenuates rapidly with radial distance from the borehole (Figure 4-4),2) there is very little outward migration of the profile in the first year compared to the first week, and 3) temperature cycling attenuates rapidly with radial distance (Figure 4-5). A11 of these observations can be explained if the volumetric heat capacities and the active mass and heat transport mechansims are analyzed. 


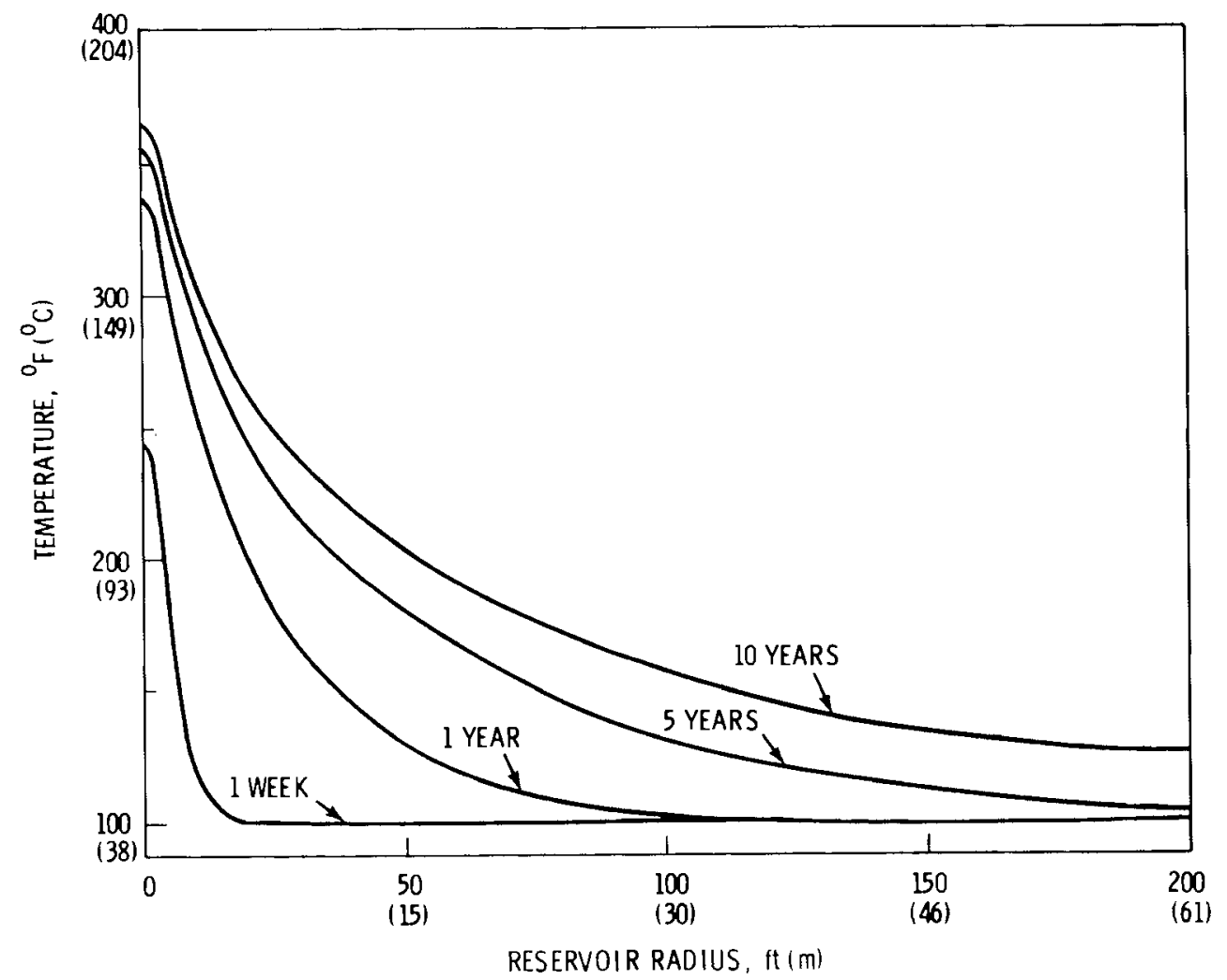

FIGURE 4-4. Radial Temperature Profile Based on a One-Dimensional Gas Flow Computer Simulation

The ideal storage zone is axially symmetric with respect to the borehole. Therefore, the volume available for the storage of thermal energy increases as a function of the radial distance to the second expontential power. Furthermore, the quantity of heat required to raise the temperature of a unit volume of the rock constituent by $1^{\circ} \mathrm{F}$ is 45 to 75 times that of an equal volume of air under expected reservoir conditions. Furthermore, the solid constituent occupies $80 \%$ of the available volume compared to $20 \%$ for the air. Thus, if one assumes that the air/rock contact area is reasonably large and that the solid constituents and the air rapidly attain thermal equilibrium, then the observed attenuation in the temperature profiles becomes very plausible. The conclusion is that the thermal energy associated with the injected airstream is essentially stored in the solid rock 


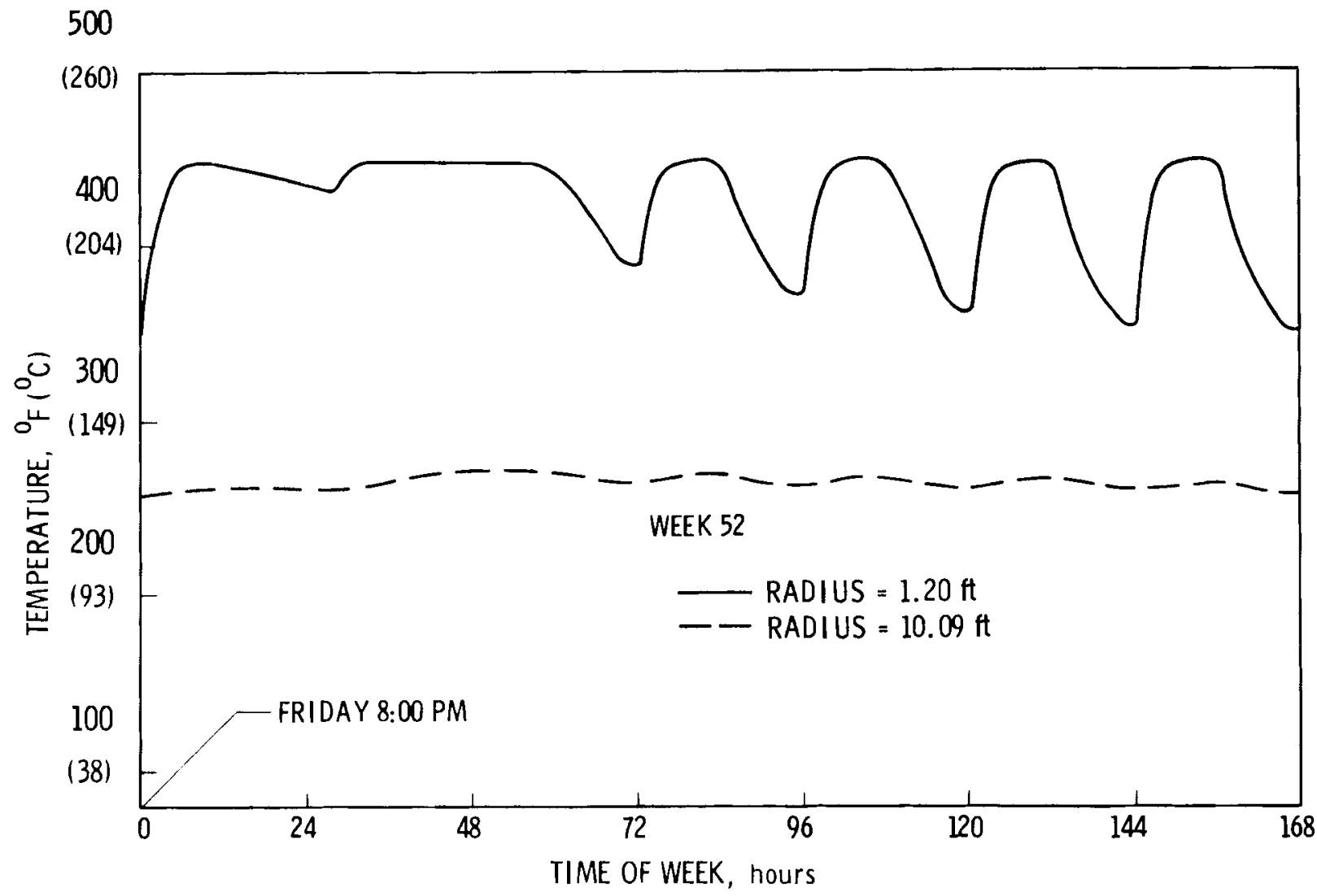

FIGURE 4-5. Temperature Cycling After One Year of Operation

constituents in a small zone around the borehole. Furthermore, if the storage zone is assumed to be totally dehydrated, then the only active transport mechanisms beyond the working air zone are solid-solid conduction and gaseous diffusion which dictate an exceedingly gradual outward migration of the temperature profile with time.

If one includes vaporization of the residual water, it can be deduced that the water acts as a heat sink, and further attenuates the temperatures within the storage zone. This will be discussed in more detail in Section 5.0 . 


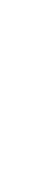




\subsection{MAJOR POTENTIAL PROBLEM AREAS IN STORAGE OF COMPRESSED AIR}

This section presents individual discussions of the major topic areas associated with reservoir design and stability criteria. The following areas are included:

- well casing and completion cement integrity

- liquid and vapor phase water

- caprock integrity

- geochemical reactions

- physical response of the storage matrix.

The following steps were followed in conducting this state-of-the-art survey: 1) all of the topics perceived as even remotely pertinent to the underground storage component of the CAES concept were listed, 2) available literature corresponding to this list of topics was collected and reviewed, 3) preliminary analytical and numerical studies were conducted to better define the physical conditions within the storage zone, 4) the complete list of topics was reviewed and discussed by a panel of reservoir engineering experts, 5) preliminary determination of the relevancy and priority of each topic was made, 6) a list of topics requiring further attention was drafted, and 7) preliminary design and stability criteria, based on these analyses, were synthesized. The topics requiring further study are biased towards high temperature storage due to the associated uncertainties and paucity of historical experience. Potential problems with the storage reservoir are considered in this report. Criteria are established that will mitigate these problems and yet minimize unnecessary restrictions on the design and operation of a CAES facility.

\subsection{WELL CASING AND COMPLETION INTEGRITY}

One of the most important problems to be addressed is the thermomechanical response of the metal well casing and the cement grouting sheath when exposed to elevated temperatures and thermal cycling.

Casing failures in the steam-drive oil recovery industry are extensively documented. Thirty such failures have been verified in California alone. 
Casing failure occurs initially when temperature-generated compressive stresses exceed the yield strength of the casing. This causes the casing material or joints to permanently deform during the fluid injection period. Subsequent cooling while the well is closed or producing relieves the compressive stress. However, the induced deformation creates a tensile stress if the casing returns to a lower temperature level. Often this tensile stress results in joint failure by fracture or pullout. (2) Figure 5-1 illustrates this general concept.

The physical principles governing casing failure are well known. The uncertainty resides in the precise temperature limits at which this failure is likely to occur. This temperature is a function of casing material properties, lateral deformation or buckling capacity, and joint performance under high compressive and tensile loads.

To lend perspective to the problem, the following general rules are given: 1) unrestrained stainless steel casing will expand $0.8 \mathrm{in.} / 100 \mathrm{ft}$ of length $/ 100^{\circ} \mathrm{F}$ temperature rise $\left(1.2 \times 10^{-3} \mathrm{~cm} / \mathrm{m} /{ }^{\circ} \mathrm{C}\right)$, and 2$)$ restrained casing will experience compressive and tensile stresses on the order of $200 \mathrm{psi} / 1^{\circ} \mathrm{F}$ temperature variation $\left(24.6\right.$ bars $/{ }^{\circ} \mathrm{C}$ ).

Table 5-1 reveals how this stress-temperature relationship defines allowable temperature changes for compressive loading for some typical casings. Any temperature increases beyond this will generally result in inelastic deformation. For CAES projects it is assumed that completion practices will preclude buckling due to lack of radial confinement.

Referring again to Figure 5-1, permanent compressive deformation occurs at temperatures exceeding $\Delta \mathrm{T}_{\mathrm{yp}}$. Any additional degree of overstressing will determine the magnitude of permanent deformation and subsequent induced tensional stress upon cooling. This temperature range is $\Delta T_{t}$ and the stress leading to failure will be equal to $200 \mathrm{psi}\left(\Delta T_{t}\right)$. Table $5-2$ reveals the range of these stresses on $\mathrm{J}$ type casing for various temperatures.

So far the analysis has assumed that the casing is totally restrained and that thermal response is manifested in high compressive stresses. The potential for casing expansion and shearing off of wellhead and surface pipes 


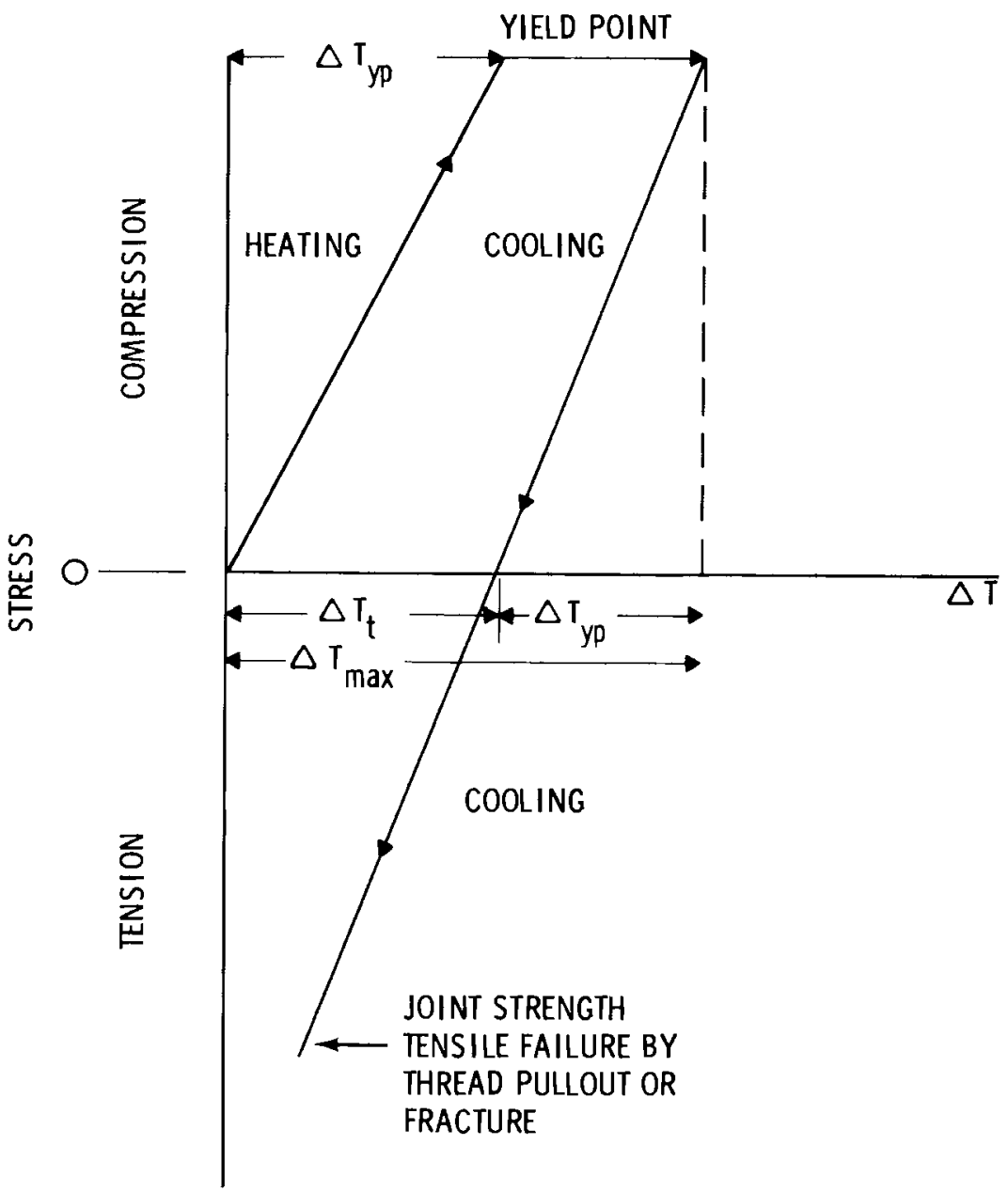

FIGURE 5-1. Stress History of Casing During Steam or Hot Air Injection(3)

TABLE 5-1. Allowable Temperature Changes for Compressive Loading(2)

\begin{tabular}{|c|c|c|}
\hline $\begin{array}{c}\text { Material } \\
\text { Grade, } \\
\text { spec } \\
\end{array}$ & $\begin{array}{c}\text { Minimum } \\
\text { Yield Stress, } \\
\text { psi }\end{array}$ & $\begin{array}{c}\text { Allowable } \\
\text { Temperature } \\
\text { Change }(\Delta T),{ }^{\circ} \mathrm{F} \\
\end{array}$ \\
\hline $\mathrm{J}$ & 55,000 & 275 \\
\hline$N$ & 80,000 & 400 \\
\hline S & 95,000 & 475 \\
\hline
\end{tabular}


TABLE 5-2. Temperature Changes/Tensile Forces Resulting from Cooling Over-Stress Pipe

\begin{tabular}{|c|c|c|c|c|}
\hline $\begin{array}{c}\text { Casing } \\
\begin{array}{c}\text { Temperature, } \\
{ }^{\circ} \mathrm{F}\end{array} \\
\end{array}$ & $\begin{array}{c}\Delta \mathrm{T}_{\max }, \\
{ }^{\circ} \mathrm{F}\end{array}$ & $\underset{{ }_{\mathrm{o}}^{\mathrm{F}}}{\Delta \mathrm{T}^{\prime}}$, & $\begin{array}{c}\Delta T_{t}, \\
{ }^{\circ} \mathrm{F} \\
\end{array}$ & $\begin{array}{c}\text { Tension when } \\
\text { Cooled, } \\
\text { psi }\end{array}$ \\
\hline 500 & 400 & 275 & 125 & 25,000 \\
\hline 550 & 450 & 275 & 175 & 35,000 \\
\hline 600 & 500 & 275 & 175 & 45,000 \\
\hline 650 & 550 & 275 & 275 & 55,000 \\
\hline
\end{tabular}

is also very real. Given a $1000-\mathrm{ft}(305-\mathrm{m})$ casing string at $650^{\circ} \mathrm{F}\left(343^{\circ} \mathrm{C}\right)$ and totally unrestrained conditions, the top of the casing can be expected to expand out of the ground approximately $4.3 \mathrm{ft}(1.3 \mathrm{~m})$.

Superimposed upon the problem of temperature induced overstressing and/or linear elastic strain response is the concept of fatigue due to thermal cycling. An example of magnitude of anticipated temperature fluctuations for a $450^{\circ} \mathrm{F}\left(232^{\circ} \mathrm{C}\right)$ charging temperature is demonstrated in Figure 4-5. Very little experimental data on casing fatigue is available at the elevated temperatures in question. However, an example of thread failure after 20 to 40 cycles on a steel similar to $\mathrm{N}-80$ casing has been documented. (3) When stress corrosion was included, this level dropped to 10 to 20 cycles.

Naturally, tensile failure during the first cycle or fatigue failure during subsequent cycles is not a problem if the compressive yield point of the casing in question is never exceeded. Therefore, the following design criteria is recommended:

- The compressive stress generated by the change in casing temperature during initial hot air injection should not exceed the yield strength of the particular casing material in question.

There are two basic methods available to permit injection of air at elevated temperatures: 
1. Design and build thermal protection into the initial well completion:

- prestress the casing in a tensional mode prior to completion,

- anchor the casing only at the bottom to allow for expansion, and

- rely on casing steel with a greater yield strength.

2. Attenuate the effective casing temperature by annular insulation and/or multiple strings.

The prestressed completion is based on the theory that enough tension (up to $80 \%$ of minimum yield strength) can be placed on the casing prior to final cementing to prevent the casing from exceeding the yield point in compression during heating. This technique certainly appears viable for a CAES project. Stress-free completion (bottom anchoring only) does not appear applicable to the problem since a good cement completion through at least the full extent of the caprock is required to maximize air containment potential. Utilization of upgraded casing materials and the various insulation and multiple strings techniques is certainly possible from an engineering standpoint. However, the cost may be prohibitive.

The problems of casing failure by joint pullout or fracture in wells have been extensively examined in the fields of steam and hot air injection for oil recovery. Design criteria have been successfully used to prevent casing failure in wells stimulated with $650^{\circ} \mathrm{F}\left(343^{\circ} \mathrm{C}\right)$ steam. ${ }^{(2)}$ Given this field experience and the rapid loss of carbon steel physical properties at or near $650^{\circ} \mathrm{F}\left(343^{\circ} \mathrm{C}\right)$, it is recommended that this temperature be considered as a maximum, at least from the standpoint of casing integrity.

The response of the cement grouting to elevated temperatures is another area requiring some thought. However, given the availability of good silica cements and completion practices, a $650^{\circ} \mathrm{F}\left(343^{\circ} \mathrm{C}\right)$ range should be attainable. There are two components to the thermal problem: 1) the elevated temperature itself and the potential for cements other than the silica-based ones to dehydrate and lose integrity, and 2) the establishment of a radial thermal gradient across the sheath. The first area appears to be manageable with the proper type of cement. The second problem may require that the injection temperature be raised gradually over many cycles. This would warm the cement 
sheath by conduction and possible preclude the establishment of high thermal stresses within the sheath.

In conclusion, the upper temperature limit for casing materials and completion cements should currently be considered as $650^{\circ} \mathrm{F}\left(343^{\circ} \mathrm{C}\right)$.

\subsection{LIQUID AND VAPOR PHASE WATER}

The humidity within the storage zone has been previously identified as an important parameter for both low and high temperature injection. This section is devoted to a discussion of: 1) the sources of the liquid and vapor phases of water, 2) the zones within the storage region where control of the humidity conditions is most vital, 3) the potential adverse consequences associated with the presence of the two phases, and 4) a mechanism for eliminating the water in the vital areas. Table 5-3 presents the various topics covered in this section.

\section{TABLE 5-3. Components of the Humidity Problem}

Potential Fluid Sources

Air Storage Zones (Figure 4-2)

Potential Adverse Consequences

Dehydration Mechanism
Residual water subsequent to initial air bubble development.

Water vapor associated with the injected air mass.

Leakage through grout seal or caprock. critical (near-wellbore) zone. Working air zone.

Cushion air zone.

Reduction in air deliverability for a given pressure gradient.

Introduction of liquid and vapor to surface facilities.

Geochemical reactions (permeability changes, corrosion, scaling).

Reduction in available thermal energy. Increased thermal diffusivity.

Cycle undersaturated air. 


\subsubsection{Sources of Liquid and Vapor Phases}

The first source of liquid is the residual content that will be present after initial development of this air bubble. Prior to air injection, the porous media is totally saturated with liquid water and some concentration of dissolved solids. If air is injected at a pressure in excess of the local interstitial fluid pressure, then a certain percentage of the pore liquids will be displaced away from the injection point and ideally will no longer be of concern. However, in regions that: 1) support only a single communication channel (throat) with the remainder of the matrix, 2) support a capillary retention force in excess of the imposed air pressure graident, or 3) are hydrualically isolated, the interstitial liquids will not be displaced by the advancing air front. This volume of water is known as the residual liquid saturation. This residual water content is typically measured in the laboratory by imposing a pressure gradient between the gas and liquid phases in capillary contact with a sink and measuring the volume of water displaced after equilibrium has been attained. The test is then repeated with an incrementally higher imposed pressure gradient. Figure 5-2 demonstrates the results of several such experiments. Note the majority of the liquid is displaced by a very small $\triangle P(<5 \mathrm{psi})$ in these specific examples, but regardless of further pressure increases the liquid saturation levels remain relatively constant. This is termed the irreducible or connate saturation level and is defined in terms of the percentage of the available pore volume occupied by liquid constituents. Figure 5-3 demonstrates how the irreducible saturation might vary as a function of sample permeability. This 1 imited data reveals that for 300 millidarcy media, the irreducible levels vary from 10 to $25 \%$. Figure 5-4 demonstrates a 35\% level for a specific 170-millidarcy sample.

Similar core tests are conducted to yield relative permeability curves as a function of interstitial liquid saturation $\left(S_{W}\right)$. Figure 5-5 shows that even for a $40 \% S_{W}$ level, the specific permeability to gas in the given sandstone sample is still on the order of $90 \%$ of the permeability with the sample totally dewatered. Unfortunately, the empirical scatter over the full spectrum of sandstone samples is such that the permeability to gas can be reduced somewhat more significantly, but the point is that the relative permeability 


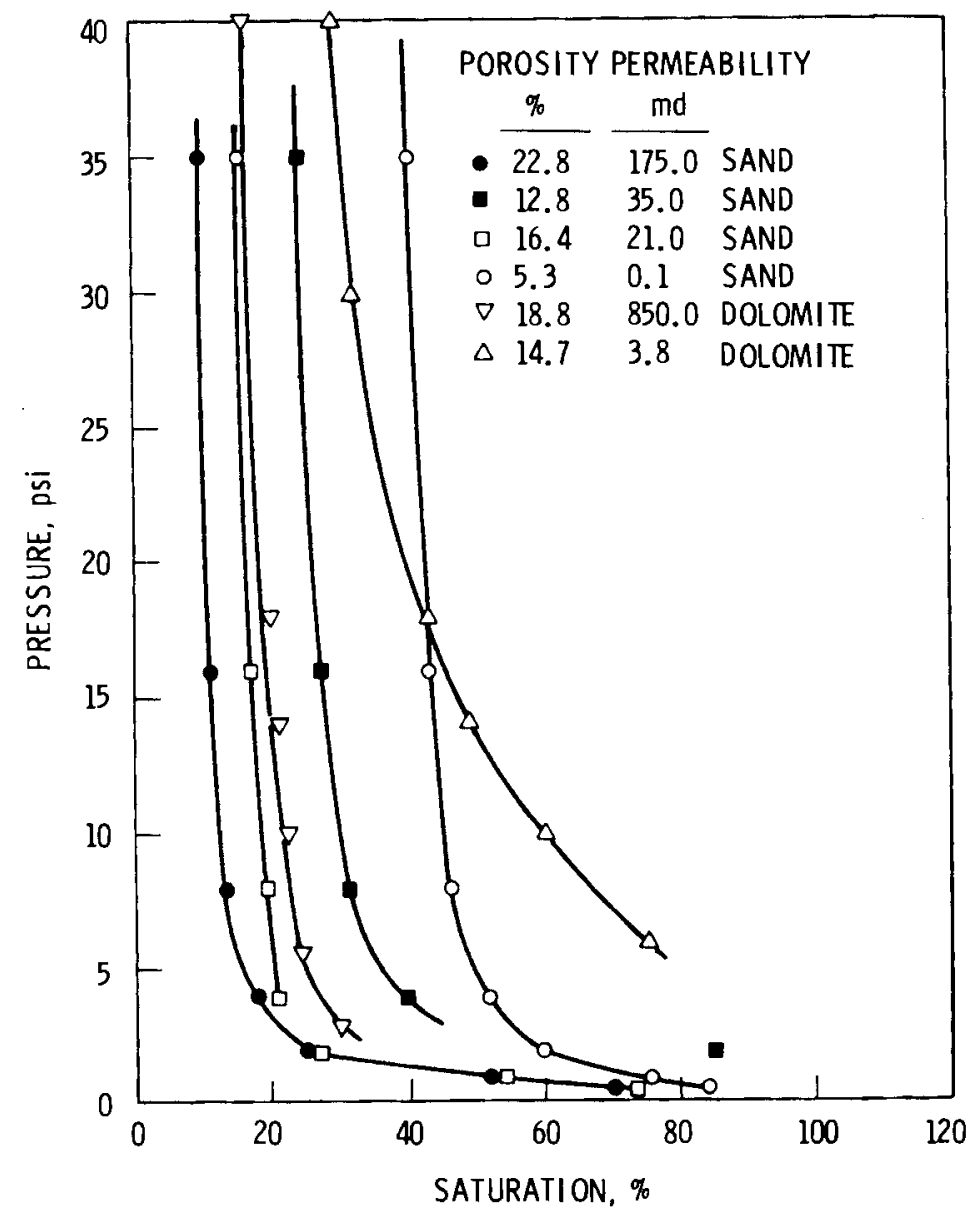

FIGURE 5-2. Miscellaneous Capillary Pressure-Saturation Curves (4)

curves are quite nonlinear and in general the permeability to gas is not drastically perturbed by a saturation level of $20 \%$ or less. Unfortunately, extrapolation of these results to field applications is not without added complexity.

In the field, the irreducible saturations tend to be somewhat higher than measured in the laboratory because a significant volume of water remains trapped in porous regions that do not support or rapidly lose hydraulic continuity before the applied capillary pressure gradient is sufficient to effect drainage. (5) Therefore, it appears that in the field, the magnitude of the irreducible wetting phase saturations are somewhat controlled by the 


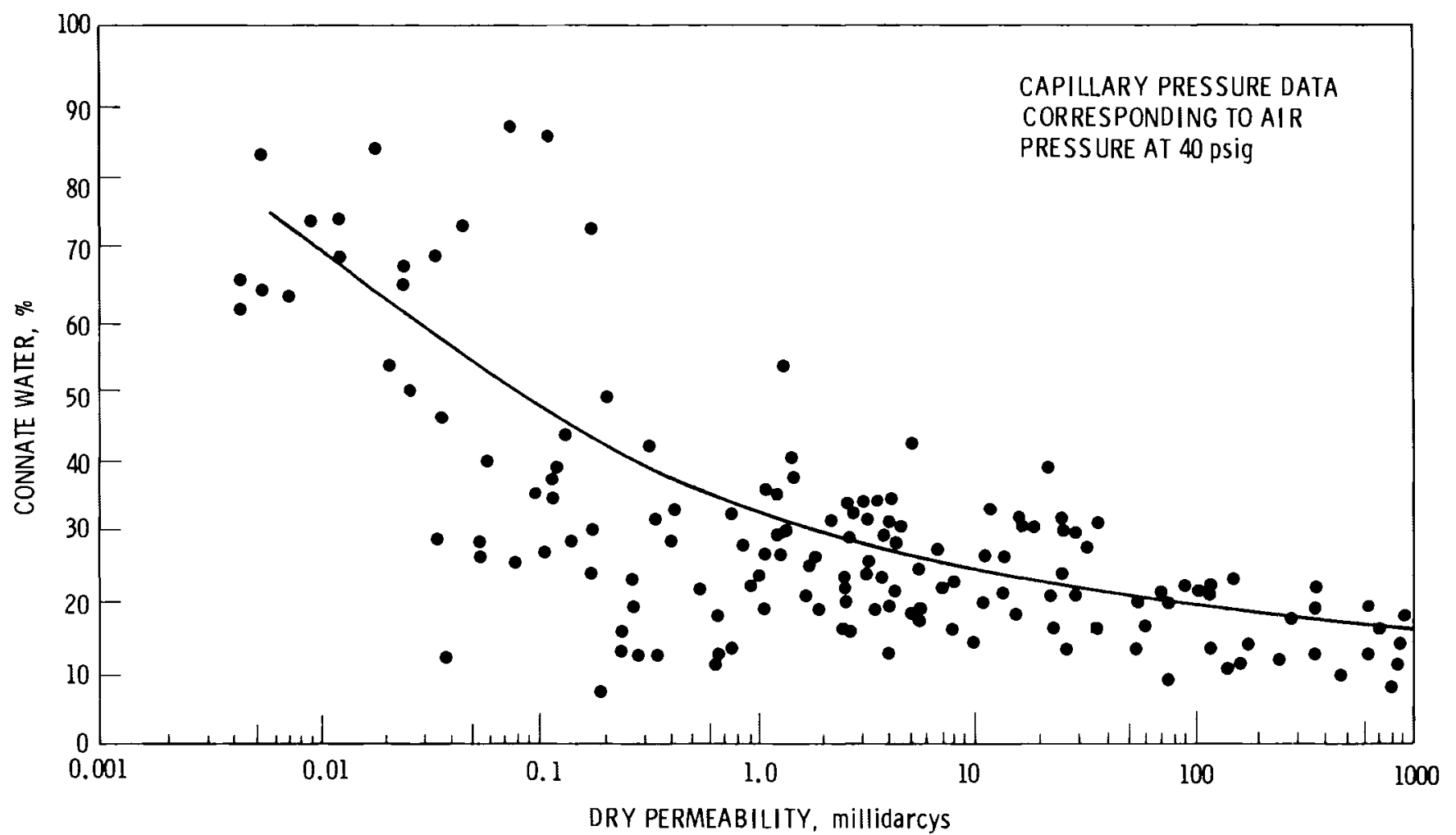

FIGURE 5-3. Permeability Versus Connate Water by Capillary Pressure ${ }^{(4)}$ 


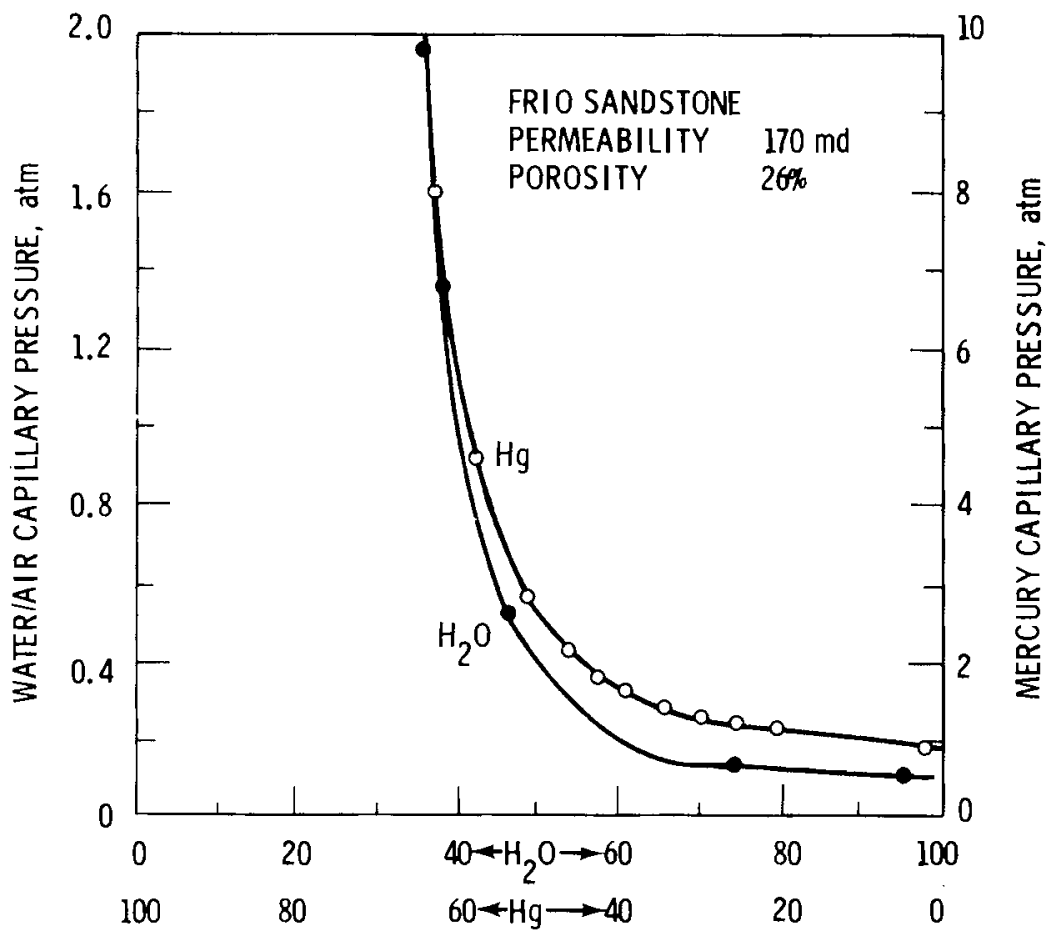

TOTAL PORE SPACE OCCUPIED BY LIQUID, \%

FIGURE 5-4. Comparison of Capillary-Pressure Results with Mercury and Air/Water(4)

variability of the porous structure and that this heterogeneity cannot be reproduced in the smal1 laboratory specimens. Figure 5-6 demonstrates in a conceptual manner how the laboratory results can be in error, and Figure 5-7 portrays the concept of hydraulic isolation. Note that as the applied capillary pressure due to the injected air mass is increased to $P_{1}$, the region $P_{1}$ is drained and the air pressure completely equilibrates around the region $\mathrm{P}_{2}$. Even as the air injection pressure is increased so that a gradient in excess of $\mathrm{P}_{2}$ might be imposed across the region $\mathrm{P}_{2}$, equilibration will occur far too rapidly in region $P_{1}$ to support the pressure gradient and displace the water from $P_{2}$. Thus $P_{2}$ will remain saturated with the liquid phase. Similarly, region $P_{3}$ will remain saturated if the imposed pressure gradient does not exceed that necessary to drain $\mathrm{P}_{4}$ even though it is great enough to drain $\mathrm{P}_{3}$. Region $\mathrm{P}_{4}$ might represent a mini-layer shale boundary. The point is that a significant amount of water is going to remain in the reservoir subsequent to 


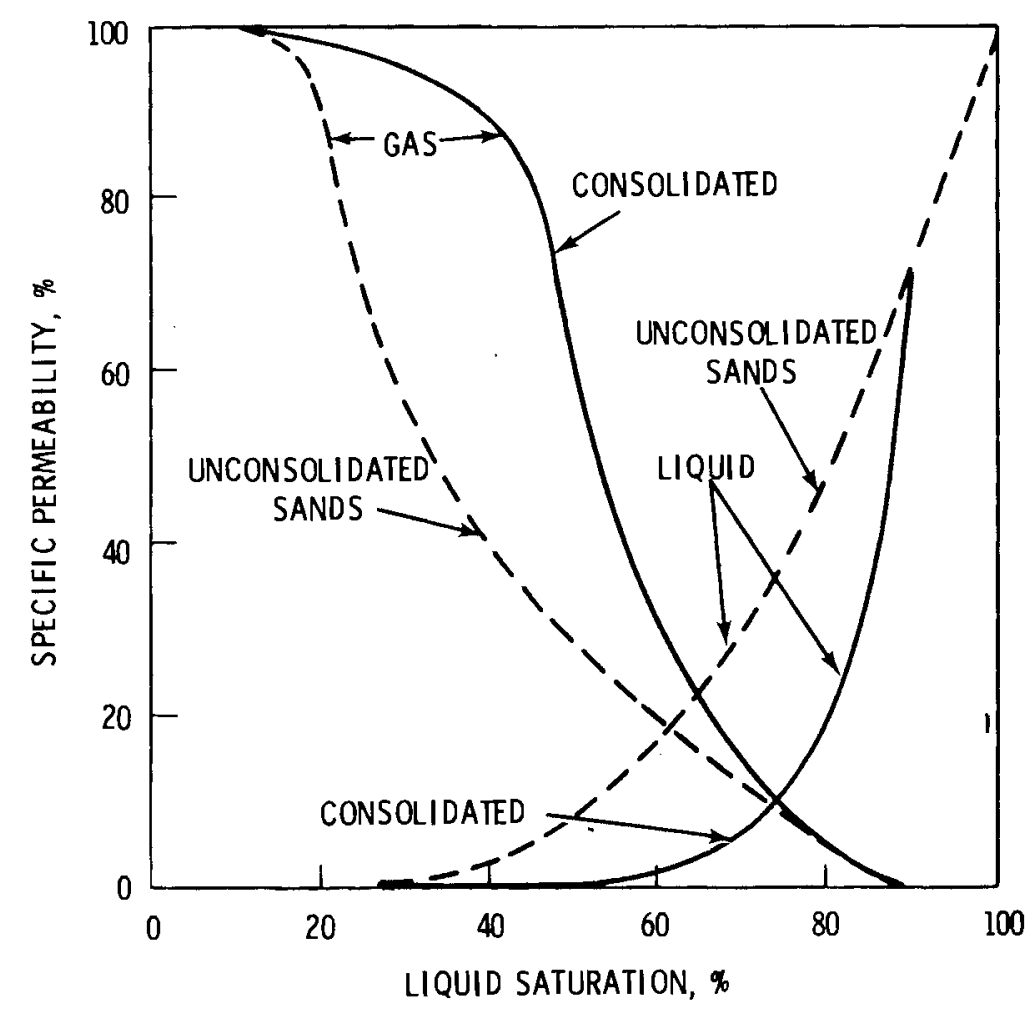

FIGURE 5-5. Relative Permeability for Consolidated and Unconsolidated Sands $(4)$
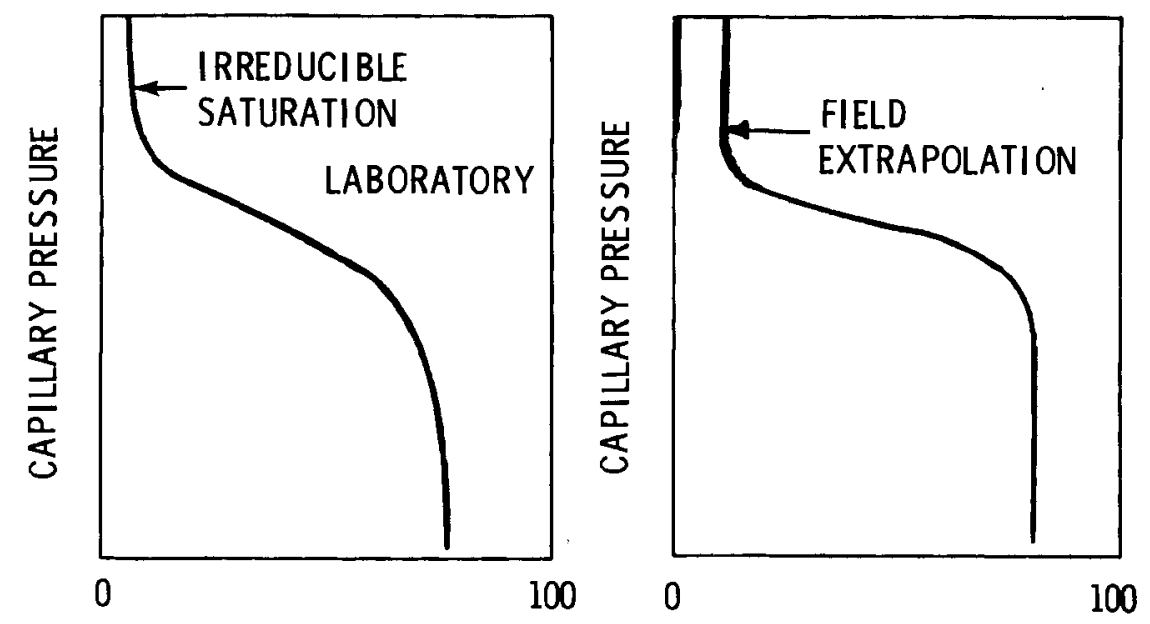

INTERSTITIAL SATURATION, \%

FIGURE 5-6. Pore Space Saturation $(5)$ 


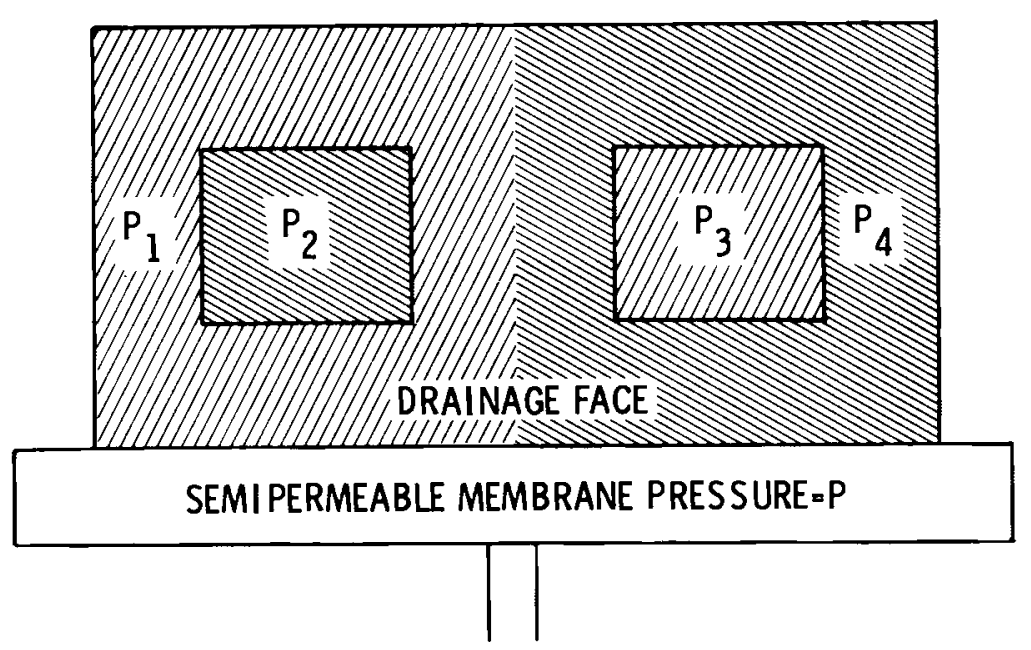

ENTRY P RESSURES $P_{1}<P_{2}<P_{3}<P_{4}$

FIGURE 5-7. A Heterogeneous Porous Mass Which Upon Drainage Retains Wetting Liquid in Region $\mathrm{P}_{2}(5)$

initial development of the air bubble and that this level will be in excess of that measured in the laboratory.

The second potential source of water is associated with the injected air mass. Moisture injected with the air will condense when proper conditions are encountered in the reservoir. This is a function of temperature, pressure, and initial humidity levels. It is anticipated that the air will be undersaturated before it is introduced to the storage matrix. However, the degree of undersaturation will be economically determined. Solid desiccants and refigeration systems may be uneconomical given the large air masses and flow rates. Therefore, cooling of the air stream to reduce its water carrying capacity, removal of the condensate, and subsequent reheating of the air may be the only realistic alternative.

To lend perspective, surface ambient air at $30 \%$ relative humidity contains approximately $6.0 \times 10^{-3} 1_{\mathrm{H}_{2} \mathrm{O}} / 1 \mathrm{~b}_{\mathrm{Air}}$. Air at $50 \mathrm{~atm}$ is totally saturated at $3.0 \times 10^{-4} 1 \mathrm{~b}_{\mathrm{H}_{2} \mathrm{O}} / 1 \mathrm{~b}_{\mathrm{Air}}$ for the same surface ambient temperature. If this mass of compressed air is heated in a heat exchanger to $450^{\circ} \mathrm{F}$ it can 
contain as much as $8.0 \times 10^{-1} 1 \mathrm{~b}_{\mathrm{H}_{2} \mathrm{O}} / 1 \mathrm{~b}_{\mathrm{Air}}$ before it is saturated. Figure $5-3$ reveals the solubility of water in air at various temperatures and pressures. Assuming the air is heated and then injected, its temperature will be reduced as it proceeds into the storage zone and the water carrying capacity will be similarly reduced. If the air contains sufficient mositure, it will begin to condense within the storage zone. The quantity and resulting saturation profile will depend on the degree of undersaturation of the injected air and the reservoir temperature and pressure profiles. Thus, there are two primary sources of liquid and vapor phase water that must be investigated. A third source, leakage around the grout seal, should be noted, but will not be addressed in this section.

\subsubsection{Air Storage Zone}

Before discussing the potential consequences associated with liquid phase water, it would be instructive to subdivide the air storage zone into three components. Figure 4-2 presents a conceptual model of the system. The critical zone is defined as the cylindrical (ideal) volume around a wellbore that exhibits high velocity airflow and elevated temperatures. The working air zone is the cylindrical (ideal) zone that contains the mass of air used in a weekly cycle. In other words, this air mass will be expanded through the turbine at least once during the week. The critical zone is naturally encompassed within the working air zone. The third division is the cushion air zone. This is defined by the volume of air that perpetually remains in the reservoir. The caprock represents an additional region susceptible to the effects of humidity and is considered in the next section. Before specifying humidity criteria for each of these zones, some insight into the potential adverse consequences associated with the liquid and vapor phases of water is required.

\subsubsection{Consequences Associated with the Wetting Phase Saturation}

The presence of interstitial liquids, especially near the wellbore, may result in a reduction of air deliverability for a given pressure gradient. For example, water saturations of $50 \%$ can reduce the specific permeability to gas by some $30 \%$ of the dry value. Field operations frequently show a reduction 


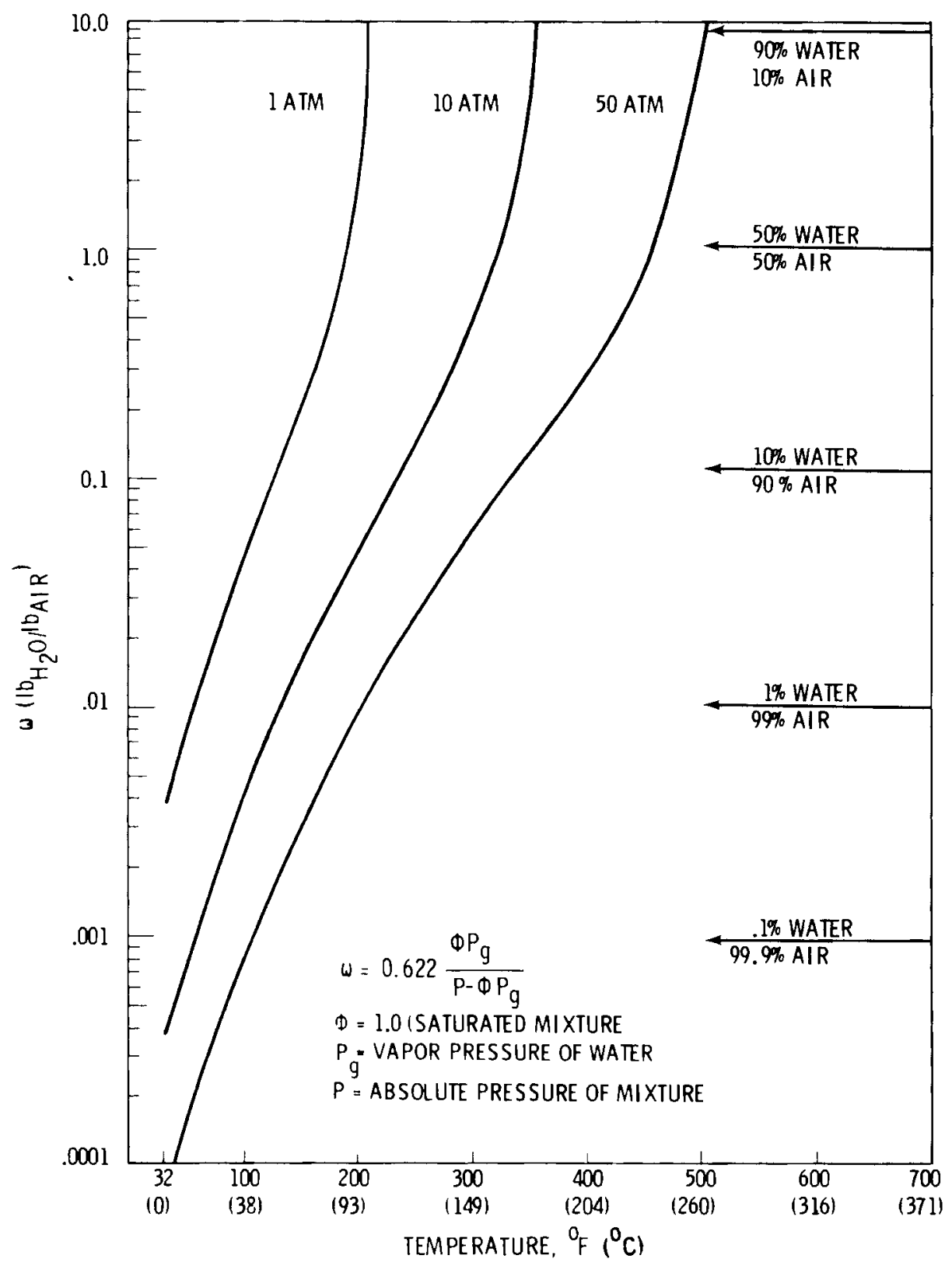

FIGURE 5-8. Solubility of Water in Air at Various Temperatures and Pressures 
of gas flow of $50 \%$ or more when 7 iquid water reaches the wellbore. (6) Under the high airflow conditions associated with CAES, the residual water may be mobile to some extent. Some of this liquid may accumulate in the wellbore or be produced with the airstream. Although the conditions are not totally analogous, water infiltration in the natural gas storage industry is often considered a significant nemesis.

The interstitial water will reduce the effective permeability to air according to the empirical relative permeability curves. In addition, it will tend to increase the turbulent flow factor $(\beta)$. This is a secondary effect, however, and may account for less than 5 to 10\% of the anticipated air deliver-ability reduction. Unfortunately, few data are available describing two-phase flow in porous media with liquid saturation under high velocity conditions.

Liquid phase water reaching the wellbore could impact normal operation in the following ways: 1) significantly increase the flowing fluid column density and thus create a severe pressure drop penalty, 2) initiate casing corrosion especially if chlorides or alkali metals are involved, 3 ) enter the turbines and combine with sulfur compounds in the fossil fuel to create adverse corrosion conditions, and/or 4) accumulate in the bottom of the well and gradually reduce airflow capacity. In general, if the fluid flow rate is greater than $5 \mathrm{ft} / \mathrm{sec}(1.5 \mathrm{~m} / \mathrm{sec})$, the 1 iquid will be produced with the airstream and the pressure drop, and corrosion effects will result. Below this velocity, the water will gravity drain out of the fluid column and will collect in the wellbore. It is anticipated that a CAES well would support a velocity in excess of the general threshold value and, therefore, water reaching the wellbore should be produced with the airstream.

Geochemical effects associated with the presence of the liquid phase are included in the next section and will not be further discussed at this time. Thermal development of the reservoir will be affected by the interstitial saturation conditions. The vaporization of the liquid will represent a heat sink and the thermal diffusivity, both real and apparent, is a function of saturation conditions.

Given $540 \mathrm{kcal} / \mathrm{kg}$ as the latent heat of vaporization of water, a cylindrical volume of radius $5 \mathrm{~m}$ and axial length $30 \mathrm{~m}$, an interstitial porosity 
of 0.20 , and 0.20 of that porosity saturated with liquid, it would require on the order of $5 \times 10^{7} \mathrm{kcal}$ of energy to achieve a total state of dehydration within the zone. Only the process of evaporation is considered in this example.

The ability to disperse this quantity of thermal energy into the storage zone depends in part on the thermal diffusivity characteristics. The effective thermal diffusivity is strongly a function of liquid phase saturation. As with all characteristics of porous media, this characteristic is extremely site specific and the scatter in results from specimen to specimen and from laboratory to the field can be dramatic. The pertinent parameters affecting the thermal diffusivity include the degree of liquid saturation, the porosity, and the conductivities of the liquid and, to a lesser extent, the solid constituents. Furthermore, temperature and confining pressure have 1 imited effects. Here we are primarily interested in the dominant parameter, that of liquid phase saturation. Figures $5-9$ and 5-10 reveal how the thermal conductivity of two specific 011 sands varies as a function of brine saturation $\mathrm{S}_{\mathrm{W}}$. Analysis of these data results in the media-specific correlation ${ }^{(7)}$ :

$$
{ }^{\tau_{S W}}=0.735-1.30 \phi+0.363{ }^{\tau_{S}} S_{W}{ }^{1 / 2}
$$

where

${ }^{\tau}{ }_{S W}=$ thermal conductivity of the system

${ }^{\tau_{s}}=$ thermal conductivity of the solid

$\phi=$ porosity

$S_{W}=$ brine saturation

It can be seen that in one case the thermal conductivity increases by a factor of six in going from the totally dry to the totally saturated conditions.

It appears that in some cases an order of magnitude variation is not unrealistic. In our own laboratory, thermal conductivity for sandy sediments has increased by a factor of five in going from a dry to a $35 \%$ saturated condition. 


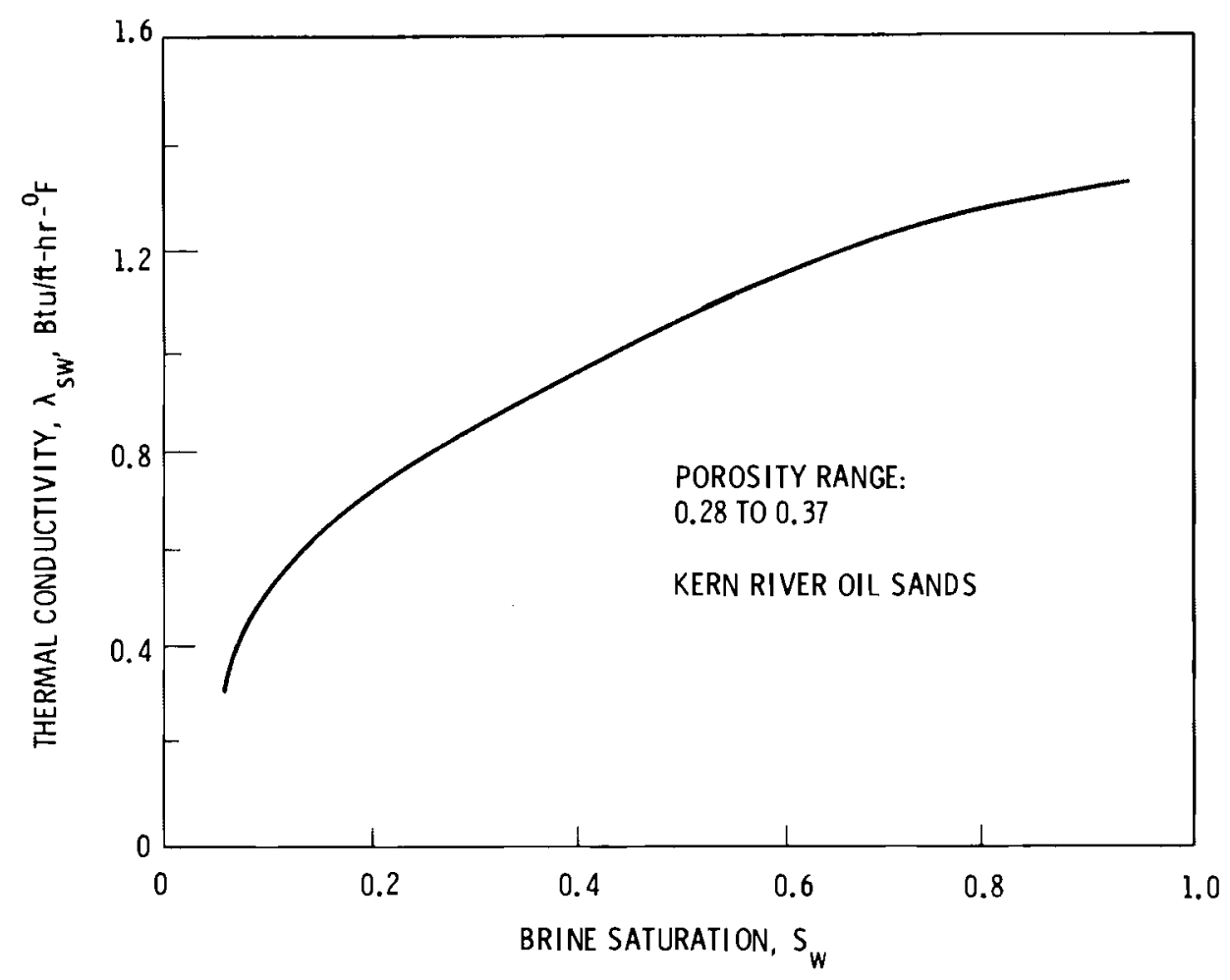

FIGURE 5-9. Thermal Conductivity of Kern River $0 i 1$ Sands (7)

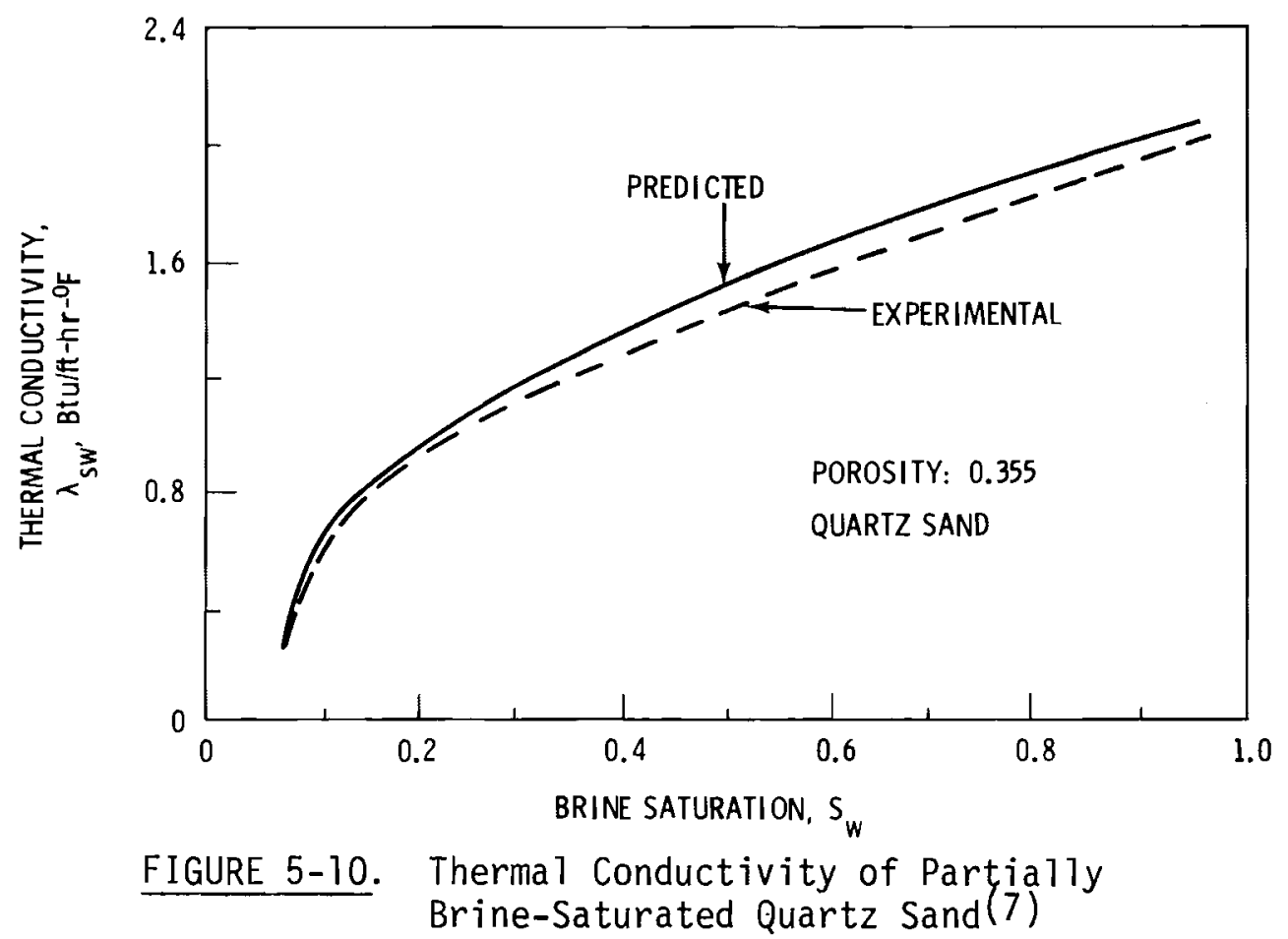


For the consolidated sandstone samples that were tested a similar analysis resulted in a fitted curve defined by:

$$
\tau\left(s_{W}\right)=\tau\left(s_{W}=0\right)+\left[\tau\left(s_{W}=1\right)-\tau\left(s_{W}=0\right) 1 s_{W}^{1 / 3}\right.
$$

where

$$
\begin{aligned}
\tau\left(s_{W}\right) & =\text { thermal conductivity at liquid saturation } S_{W} \\
\tau\left(S_{W}=0\right) & =\text { thermal conductivity of the dry sample } \\
\tau\left(s_{W}=1\right) & =\text { thermal conductivity of a fully brine-saturated sample } \\
S_{W} & =\text { fractional brine saturation }
\end{aligned}
$$

Unfortunately, no numerical coefficients were reported for consolidated specimens. It must be reiterated that these results are very site and media specific. Sandstone chemical and physical properties are dispersed over a broad spectrum. However, in general brine-air saturation systems, thermal conductivity is related to the cube root of brine saturation for consolidated media. For unconsolidated sands saturated with air and brine, the trend was as the square root of the wetting phase saturation. (a)

Al1 of the consequences mentioned above are primarily concerned with the critical or near-wellbore zone. In the remainder of the working air zone and in the cushion air zone, the adverse effects associated with residual liquid saturation should be limited to a reduction in the available air storage capacity. This conclusion is based on the following observations: 1) away from the wellbore region air mass flow rates are low through any given unit volume of rock, and 2) the temperature should be radically attenuated in relation to that in the region near the wellbore. These observations do not take into consideration the influx of liquid water due to forced-flow migration and the condensation of vapor that was evaporated from regions

(a) Note that if the temperature is raised to near the in-situ boiling point of the fluids at the given pressure, then the effective heat transfer is drastically increased by the heat pipe effect. In other words, the water is vaporized, the vapor travels down the thermal gradient, condenses, and then the liquid is drawn back along the capillary pressure gradient. A somewhat less dramatic version of this process may occur if one considers liquid migration in response to a temperature gradient. 
nearer the wellbore. In addition, the impact of anisotropy and gravity drainage barriers is also unexplored. These topics should be further addressed during subsequent investigations.

\subsubsection{Dehydration Mechanism}

So far the discussion has centered around the fluid sources, the different air storage zones, and the consequences of the residual water in each zone. Since dehydration of the near-wellbore zone has been identified as necessary, it is instructive to explore a potential mechanism by which this state can be attained. Figure 5-11 conceptually portrays the evaporation process.

Note that the presence of the thermal gradient in itself does not induce liquid or vapor migration. There may be some vertical density stratification, but there is no density instability process driving radially oriented convective transport. What the temperature near the wellbore does affect is the vapor carrying capacity of the flowing air (Figure 5-8). Evaporated water will be swept out into the storage matrix whereupon it will condense due to the decreasing temperature. This condensate will not be part of the residual water and will be free to migrate due to gravity drainage and/or capillary forces.

When the air is then produced, it will be swept back through the nearwellbore region whereupon it will be heated and thus able to carry more water vapor. This air-vapor mixture will then be produced in the wellbore. Thus, if one begins by injecting undersaturated air, the residual water near the wellbore will be in part displaced in the vapor state both during the injection and withdrawal parts of the cycle. It is this dehydration process with initially undersaturated air that will enable the near-wellbore region to be free of the interstitial liquid phase.

Obviously, the length of time to effect this dewatering is of extreme importance. The time is a function of: 1) the degree of undersaturation of the injected air, 2) the temperature and pressure of the injected air, 3 ) the temperature and pressure profiles within the storage zone, and 4) the mass flow rate and the air vapor contact area. 

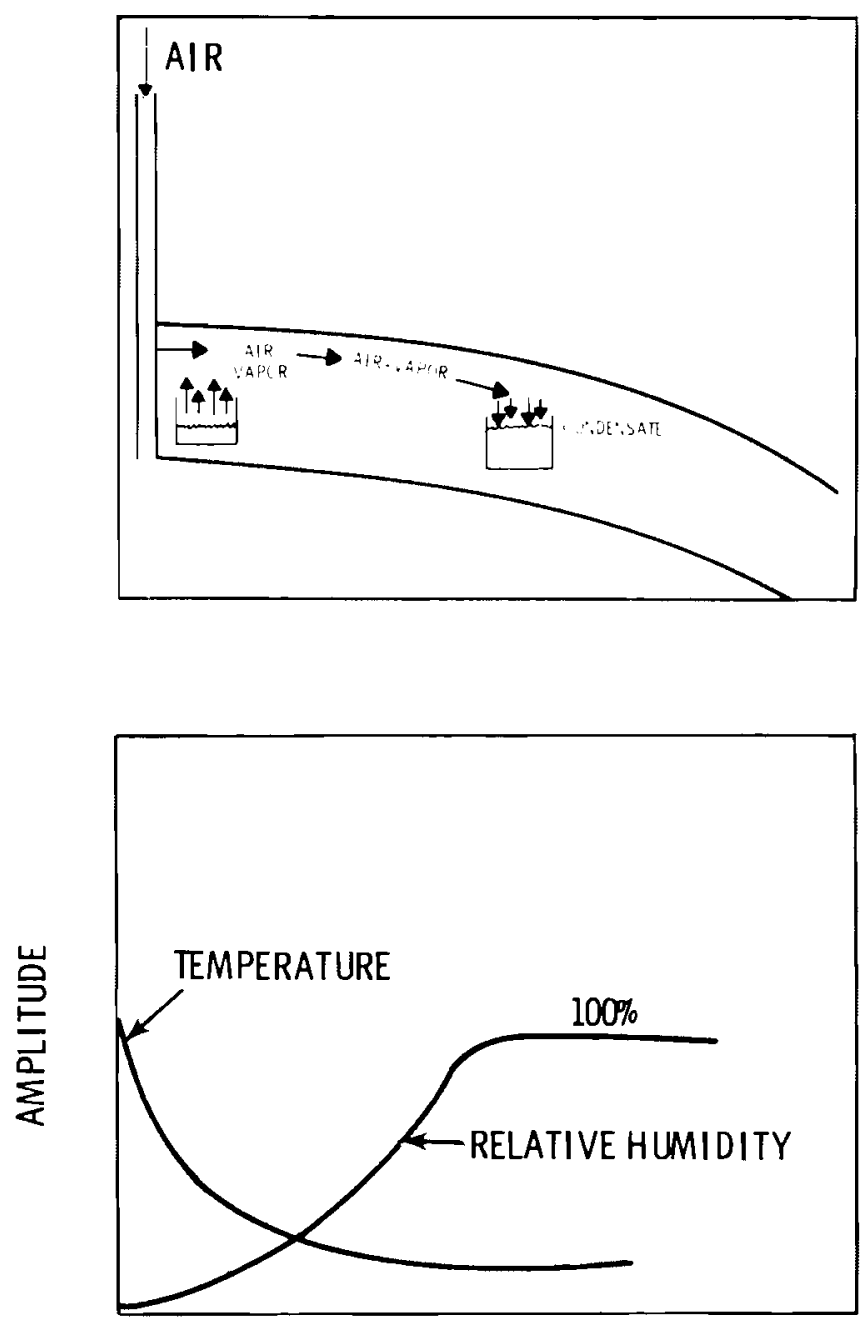

RADIAL DISTANCE

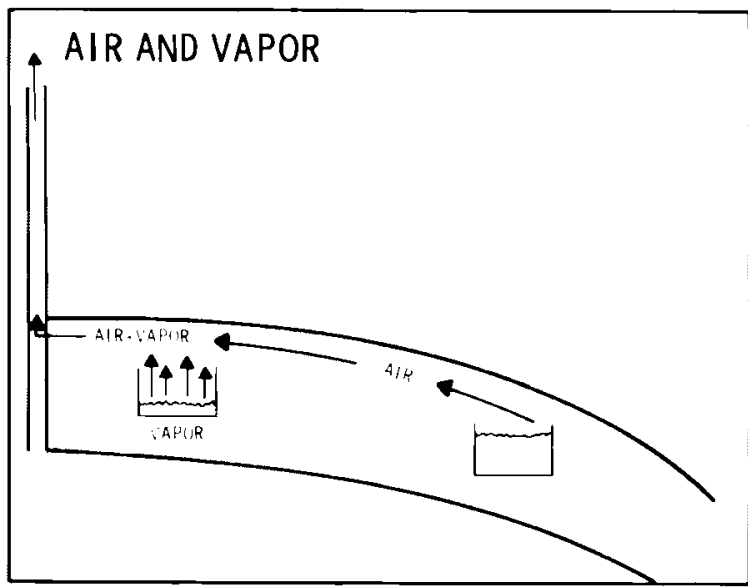

FIGURE 5-11. Conceptual Presentation of the Evaporation Process 
Two phase thermal/fluid flow numerical models and experimental efforts are necessary to address this complex problem. However, a simple computer simulation was devised to address the problem on a preliminary basis. Totally dehydrated air was injected into a storage zone that contained $20 \%$ residual water. The radial temperature profile was assumed, even initially, to be that shown in Figure 4-4. Thus, the temperature varied as a function of radial distance from $450^{\circ} \mathrm{F}\left(232^{\circ} \mathrm{C}\right)$ to reservoir ambient over a radial distance of approximately $75 \mathrm{ft}(25 \mathrm{~m})$. Reservoir pressure was assumed to follow a weekly injection-production schedule cycled around a $50 \mathrm{~atm}$ (50 bar) mean. A11 other parameters were identical to the one-dimensional air phase simulation program described earlier. The air mass was allowed to equilibrate (totally saturate) at the given temperature and pressure, and was then withdrawn from the reservoir. This rough calculation ignored: 1) the thermal energy utilized in the evaporation of the liquid phase water, 2) the associated attenuation of the storage temperatures, 3) the potential for the air to remain undersaturated due to high flow rates or poor contact with the water, and 4) the displacement of vapor down the thermal gradient. Although gross assumptions, they appear to be conservative in terms of the rate of dehydration that can be expected within the working air zone. One additional assumption necessary for the rough calculation was that the drying front be constrained to advance as a rigid boundary. This would clearly not be the case under actual conditions.

The results reveal that with $450^{\circ} \mathrm{F}\left(232^{\circ} \mathrm{C}\right)$ dehydrated air being injected, the storage zone would be dehydrated to a radial distance of $22 \mathrm{ft}(7 \mathrm{~m})$ after the first year. However, because of the temperature decreasing radially within the zone, it will require approximately 9 years to dehydrate a total distance of $40 \mathrm{ft}(15 \mathrm{~m})$. Similar calculations for $150^{\circ} \mathrm{F}\left(66^{\circ} \mathrm{C}\right)$ injected air demonstrated that it would take decades to dehydrate the same $40-\mathrm{ft}(22-\mathrm{m})$ zone.

These calculations were merely designed as a guide and prelude to the sophisticated simulation efforts that will be required to properly address the problem. However, they do demonstrate that a minimum operating temperature criterion may be necessary to ensure that the critical zone is dewatered in an expedient manner. 
The luss of storage capacity, air deliverability, and available thermal energy, as well as the large quantities of water vapor being produced have been advanced as potential problems associated with liquid phise water. An additional adverse impact involves liquid phase water as a catalyst for geochemical reactions. The result may be degradation of interstitial and/or fracture permeability, well casing material, and surface facilities. These reactions and consequences will be discussed in detail in Section 5.4 of this report.

In conclusion:

- As much as 10 to $30 \%$ of the available porosity will be occupied by residual water after initial air bubble development.

- The wellbore and critical zone must be dehydrated and perpetually maintained in that state.

- Consequences associated with liquid water include: loss of air deliverability, introduction of liquid and vapor to surface facilities, geochemical reactions, and significant changes in the thermal development of the reservoir.

- The remaining part of the working air zone and the cushion bubble zone need not be dehydrated. The residual water will be essentially immobile in its 1 iquid state.

- A minimum injection temperature may be required to ensure that dehydration of the critical zone be accomplished in an expedient manner.

- The degree of undersaturation of the injected air and the temperature profile within the storage reservoir must be such that the net transport of water vapor is out of the working air zone into the cushion zone or up the wells.

- Evaporation of residual water may result in a significant thermal energy loss and a source of vapor that may be transported up the wells.

- Thermal diffusivity and, therefore, reservoir thermal development is strongly dependent on the presence of liquid water. 
- Numerical modeling is required to characterize the anticipated conditions within the reservoir. Also, the impact of reservoir heterogeneity and anisotropy must be addressed.

- Laboratory and field scale testing will ultimately be required.

\subsection{CAPROCK INTEGRITY}

Figure 5-12 demonstrates two different mechanisms for exposing a shale caprock to elevated temperatures, and these will be assessed independently. First, there can be thermal losses in a radial direction from the well as the high temperature air flows downwards. Conduction of this thermal energy will result in elevated temperatures in the cement sheath and an interfacing cylindrical zone of shale caprock. If the temperature so attained is sufficient to induce physical and chemical degradation, loss of containment capacity may result. The second area requiring analysis is the thermal interaction between the storage zone and the overlying caprock. In general, this is considered to be a comparatively minor problem for reasons that will be discussed subsequently.

Heat losses in the radial direction associated with the injected air mass are reasonably well understood and are amenable to analytical calculations. (8) The primary mechanism for heat transfer will be transient radial conduction. The unsteady state nature comes from the fact that the cylindrical zone will increase in temperature and therefore decrease in terms of thermal conductivity. This will attenuate further heat loss magnitudes with time. The important point is that al though energy losses are insignificant in themselves, exposing a segment of shale to excessive temperatures over the full vertical extent of the caprock could have adverse consequences. Therefore, this maximum permissible temperature level must be established.

Ramey postulates and derives the solution for the following heat transmission problem. (8) A fluid is injected down a tubing of known characteristics in a well which is cased to the top of the injection interval. It is assumed that the fluid is injected at known rates and surface temperatures. The problem is to determine the temperature of the injected fluid as a function of depth and time. The solution results in quantification of the amount 


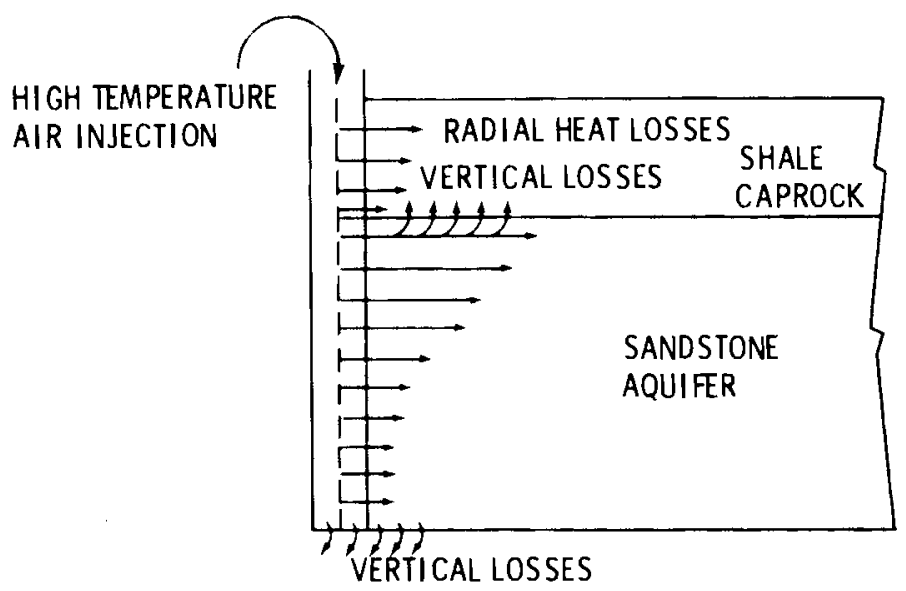

FIGURE 5-12. Mechanism for Exposing the Caprock to Elevated Temperatures

of thermal energy lost in transit down the borehole. The solution for single phase air injection ${ }^{(a)}$ is:

$$
T_{1}(z, t)=a z+b-A\left(a+\frac{1}{778 c}\right)+\left[T_{0}-b+A\left(a+\frac{1}{778 c}\right)\right] e^{-z / A}
$$

$$
\text { where } \begin{aligned}
A & =\frac{W c\left[k+r_{1} U f(t)\right]}{2 \pi r_{1} U k} \\
T_{1} & =\text { temperature of fluid in the tubing, }{ }^{\circ} \mathrm{F} \\
Z & =\text { depth below the surface, } \mathrm{ft} \\
t & =\text { time from start of injection, days } \\
a & =\text { geothermal gradient, }{ }^{\circ} \mathrm{F} / \mathrm{ft} \\
b & =\text { surface geothermal temperature } \\
C & =\text { specific heat at constant pressure of fluid, Btu/lb- }{ }^{\circ} \mathrm{F} \\
A & =\text { time function, ft } \\
T_{0} & =\text { surface temperature of the injected fluid, }{ }^{\circ} \mathrm{F} \\
W & =\text { fluid injection rate, } 1 \mathrm{~b} / \text { day } \\
k & =\text { thermal conductivity of the earth, Btu/day-ft- }{ }^{\circ} \mathrm{F} \\
r_{1} & =\text { inside radius of tubing, ft }
\end{aligned}
$$

(a) If liquid either condenses or vaporizes in the well, the effective heat capacity of the air will change appreciably and the above solution is no longer valid. 
$f(t)=$ transient heat conduction time function for earth, dimensionless

$U=$ overall heat transfer coefficient between the inside of the tubing and the outside of the casing based on $r_{7}$, Btu/day-sq $f t-{ }^{\circ} \mathrm{F}$.

This solution is based on the assumption that physical and thermal properties of the rock and wellbore materials are static, that heat will transfer only radially into the earth, and that heat transmission in the immediate vicinity of the borehole is rapid enough to be considered steady state.

This approximate analytical calculation replaces the requirement for numerical evaluation of a set of two simultaneous, linear partial differential equations and is relatively straightforward with the possible exception of the overall heat transfer coefficient U. This coefficient considers the effect of thermal resistances in the wellbore which can be very important in certain cases.

Figure 5-13 presents a comparison of measured and computed temperatures for injection of hot natural gas down insulated tubing. ${ }^{(8)}$ During the year and a half this test was operated, the temperature of the injected gas was increased to almost $500^{\circ} \mathrm{F}\left(260^{\circ} \mathrm{C}\right)$ and the gas injection rate varied from 0.8 to $16.0 \times 10^{6} \mathrm{lbm} /$ day $\left(0.4\right.$ to $7.2 \times 10^{6} \mathrm{~kg} /$ day $)$. Gas was injected down $3-i n$. $(8-\mathrm{cm})$ tubing. The annulus between the tubing and the $7-i n .(18-\mathrm{cm})$ casing was filled with Perlite insulation. This example illustrates the magnitude of potential wellbore heat losses during hot, noncondensible gas injection.

Figure 2-1 reveals the liquid/vapor relationship for water as a function of pressure and temperature. If the air is not highly undersaturated and the wellbore heat losses are of sufficient magnitude, the potential for condensation in the wellbore exists. This would tend to increase the heat transfer coefficient and, therefore, increase subsequent heat losses.

The primary concern is not the loss in energy available to the system for useful work, since this will attenuate rapidly with time. What is of concern is that a cylindrical zone of shale caprock interfacing with the wellbore may be exposed to elevated temperature due to solid-solid conduction 


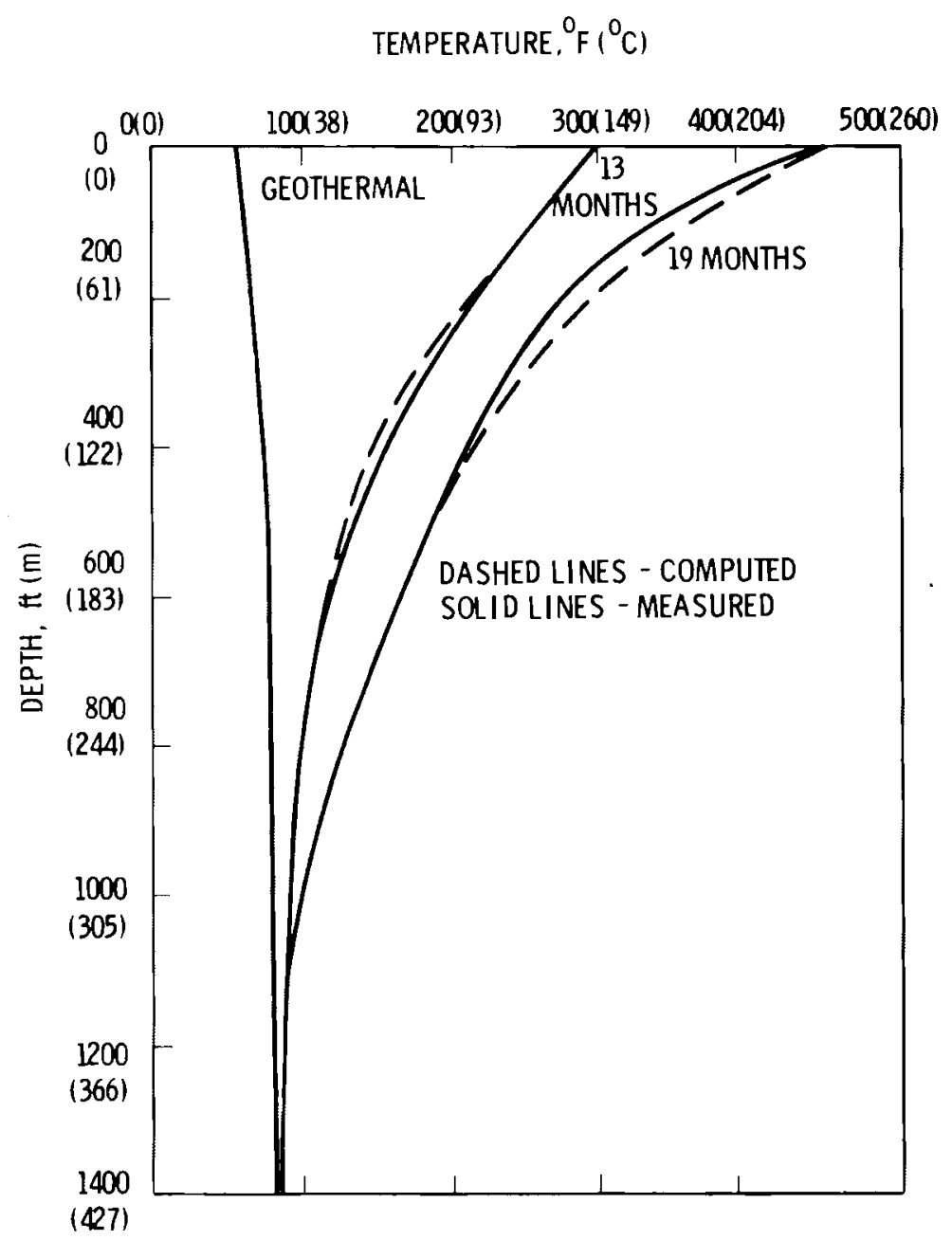

FIGURE 5-13. Measured and Computed Temperature-Depth Profile for Hot Natural Gas Injection Down an Insulated Tubing (8)

of the thermal energy. Dehydration of the interstitial fluids and/or cracking due to thermal stresses may result in the loss of containment capacity. A proposed operating criterion might be that the combination of high injection temperatures and radial heat conduction into the shale zone must be such that the rock materials are not heated beyond the levels that would induce dehydration and that gradients sufficient to cause cracking be avoided.

Assuming that interstitial water vaporization is avoided, one must sti11 address the potential for adverse chemical (hydrolytic and redox) reactions that could conceivably lead to degradation of this cylindrical caprock zone, the casing material, and surface facilities. A laboratory experimental 
program is currently being initiated to investigate this potential problem and the operating restrictions it could impose on a CAES project. Some of the pertinent reactions are discussed in the geochemical section of this report.

The second mechanism for potential caprock degradation involves vertical heat losses from the storage zone into the overlying caprock. At this interface zone, elevated temperatures, liquid phase water, and free oxygen and carbon dioxide may all be present to some degree. Under these conditions, migration of the water/air interface zone, adverse chemical reactions, and some physical degradation will probably occur. However, the following argument is presented to suggest that these conditions can be expected to terminate after a distance of a meter or so into the caprock.

The permeability in the storage zone is on the order of hundreds of millidarcys. It is overlain by a caprock zone graduating down to $10^{-4}$ to $10^{-6}$ millidarcys $\left(10^{-19}\right.$ to $\left.10^{-21} \mathrm{~m}^{2}\right)$. It is this caprock storage zone permeability contrast that is important. This fact, coupled with a relatively small delta pressure, results in the air flowing within the storage horizon (path of least resistance) and not within the caprock zone.

This concept suggests that there are no advective mass or heat transfer mechanisms operating within the majority of the caprock. The heated air mass has far less resistance to flow in the radial direction and, therefore, is primarily confined to the storage zone. As a result, the only significant heat and mass transfer mechanisms in the caprock are solid-solid conduction and gaseous diffusion.

Thus, it appears that the temperature profile in the caprock will be reduced essentially to ambient after a meter or so. Various geochemical reactions will occur in the $1-$ to $2-\mathrm{m}$ zone and a certain percentage of the generated products may get back to the borehole via gaseous diffusion. However, there will be a finite source of these products, specifically in the elevated temperature zone near the borehole, and once the source material has been depleted the reactions will essentially cease. In other words, 
degradation of the caprock and production of adverse geochemical products is limited. This "flow by" concept can be extrapolated to any macroscopic fracture flow system as well, so no steady state degradation of the shale material bounding a preferential flow path (fracture) should occur.

One additional point that should be addressed with analytical techniques is the effect of differential expansion. If the expansion of the storage zone relative to the cold caprock is large enough to induce tensile and shear stresses in the caprock, then fracturing might result.

These conclusions are based solely on experience and judgment of the research team and the panel of consultants. To validate this important concept, computer modeling and laboratory experimentation are required.

In conclusion:

- There are no apparent problems associated with the caprock for low temperature storage.

- The potential for physical and chemical degradation of the cylindrical caprock zone interfacing with the wellbore cannot presently be dismissed for high temperature storage.

- At the interface between the storage horizon and the caprock, shale material may experience physical and chemical degradation with elevated temperatures over a small vertical span, but significant deterioration beyond this should not occur.

\subsection{GEOCHEMICAL REACTIONS}

The potential for cospatial existence of elevated temperatures, readily available free oxygen and carbon dioxide, liquid phase water, and sandstone or shale deem it necessary to address geochemical reactions and potential consequences to a CAES facility. In essence this is a perfect environment for classical chemical weathering reactions. From a purely chemical standpoint, elimination of the liquid phase water and/or reduction of the temperature to a level below 70 to $90^{\circ} \mathrm{C}$ would result in an uninteresting system. In other words, the temperture and saturation conditions are key parameters. 
The following items are presented as motivation for conducting an experimental geochemical investigation:

- Thermal/chemical alterations could perturb matrix permeability, corrosion potential and/or scaling potential.

- The near-wellbore (critical zone) must be dehydrated to preclude the occurrence of thermal/chemical alterations. To do this, there is a tradeoff between temperature and time, as was previously discussed. As one increases the temperature to dehydrate, the chemical reaction rates also increase.

- During the evaporation process, the concentration of dissolved solids will increase and ultimately all of the constituents will be deposited within the matrix. Compound descriptions and anticipated quantities should be predicted.

This section is devoted to a discussion of some of the potential reactions anticipated in sandstone and shale and the associated consequences.

\subsubsection{Silicate and Carbonate Hydrolysis}

Silicate and carbonate hydrolysis is one of the most important mineral reactions to be considered. It is not uncommon for sandstone to contain silicate minerals composing $20 \%$ or more. Hydrogen ions in solution are exchanged for alkali ( $\mathrm{Na}, \mathrm{K}$ ) and alkaline ( $\mathrm{Ca}, \mathrm{Mg}$ ) cations in the silicate rock minerals. For example, forsterite, a magnesium silicate, can be hydrolyzed to yield free magnesium cations, hydroxide ions and silicic acid.

$$
\mathrm{Mg}_{2} \mathrm{SiO}_{4}+4 \mathrm{H}_{2} \mathrm{O} \longrightarrow 2 \mathrm{Mg}^{++}+4 \mathrm{OH}^{-}+\mathrm{H}_{4} \mathrm{SiO}_{4}
$$

In addition, the rapid transformation of siliceous minerals to mobile and potentially swellable and dispersive smectite (clay) species may be of concern. This may result in permeability reduction by the plugging of intersticies. For example, kaolinite (clay) is produced from a potassium silicate by the following simplified reaction:

$$
4 \mathrm{KATSi}_{3} \mathrm{O}_{8}+22 \mathrm{H}_{2} \mathrm{O} \longrightarrow 4 \mathrm{~K}^{+}+4 \mathrm{OH}^{-}+\mathrm{Al}_{4} \mathrm{Si}_{4} \mathrm{O}_{10}(\mathrm{OH})_{8}+8 \mathrm{H}_{4} \mathrm{SiO}_{4}
$$


These hydrolysis reactions are strongly $\mathrm{pH}$ dependent. During compressed air storage, oxygen, carbon dioxide and nitrogen will be introduced. Resulting reactions, such as

$$
\begin{aligned}
& \mathrm{CO}_{2} \text { (dissolved) }+\mathrm{H}_{2} \mathrm{O} \rightleftarrows \mathrm{H}_{2} \mathrm{CO}_{3} \\
& \mathrm{H}_{2} \mathrm{CO}_{3} \rightleftarrows \mathrm{H}^{+}+\mathrm{HCO}_{3}^{-} \\
& \mathrm{HCO}_{3}^{-} \rightleftharpoons \mathrm{H}^{+}+\mathrm{CO}_{3}=
\end{aligned}
$$

will increase the hydrogen ion concentration which in turn increases the degree of silicate hydrolysis.

Hydrolysis reactions are also strongly temperature dependent. In general, the reaction rate doubles for every $10^{\circ} \mathrm{C}$ temperature increment. In essence, the elevated temperatures tend to greatly accelerate natural chemical weathering reactions. In summary, hydrolysis reactions will result in: 1) an alkaline or at least a less acidic solution, 2) potentially swellable clay minerals and other residual solids, and 3 ) cations and weak silicic acid in solution.

\subsubsection{Oxidation/Reduction Reactions}

Most geothermal environments tend to be reducing in nature. In a CAES aquifer facility, on the other hand, free oxygen will be readily available. Silicate, carbonate, and sulfide oxidation reaction may thus occur. This can result in the production of insoluble compounds that may plug the reservoir and increased quantities of silicic and carbonic acid. For example, the iron silicate (fayalite) will oxidize to the insoluble ferric oxide and will also produce silicic acid.

$$
\mathrm{FeSiO}_{4}+1 / 2 \mathrm{O}_{2}+2 \mathrm{H}_{2} \mathrm{O} \rightleftharpoons \mathrm{Fe}_{2} \mathrm{O}_{3}+\mathrm{H}_{4} \mathrm{SiO}_{4}
$$

In a similar fashion, the manganese carbonate (rhodochrosite) will oxidize to yield insoluble magnesium oxide and carbonic acid.

$$
\mathrm{MnCO}_{3}+\mathrm{I} / 2 \mathrm{O}_{2}+\mathrm{H}_{2} \mathrm{O} \rightleftarrows \mathrm{MnO}_{2}+\mathrm{H}_{2} \mathrm{CO}_{3} .
$$


Of special concern is the oxidation of sulfide minerals such as lead sulfide (galena) and iron sulfide (pyrite). Pyrite often occurs in shale material. The oxidation reaction produces sulfate ions which can result in the production of sulfuric acid. It is not unusual to go from a pH of 6.0 to a pH of 1.0 to 2.0 if this reaction takes place.

$$
2 \mathrm{FeS}_{2}+\frac{15}{2} \mathrm{O}_{2}+4 \mathrm{H}_{2} \mathrm{O} \rightleftharpoons \mathrm{Fe}_{2} \mathrm{O}_{3}+4 \mathrm{SO}_{4}=+8 \mathrm{H}^{+}
$$

In summary, oxidation reactions can result in: 1) precipitation of insoluble oxides and hydroxides, 2) production of silicic, carbonic, or sulfuric acid, and 3 ) further acid production by hydrolysis of any free metal ions.

\subsubsection{General Corrosion and Scaling}

Stress corrosion due to heated chloride solutions and the severe scaling problems associated with silica and calcite are well known in the geothermal industry. How pertinent these processes might be to a CAES facility is not as yet certain. The obvious keys are the liquid saturation and mobility properties within the air bubble where the elevated temperatures occur. In other words, these reactions are highly temperature and saturation dependent. Figure 5-14 shows how the equilibrium constant for quartz (most common sandstone constituent) and amorphous silica dissolution vary with temperature.

\subsubsection{Smectite (Clay) Swelling}

The generation of clay minerals has already been discussed. Some further attention should be given to clay minerals that may exist in the reservoir at the time of initial air bubble development. A property of these compounds is their tendency to swell as the formation water is decreased in salinity. Laboratory tests, utilizing extreme conditions, have resulted in as much as $88 \%$ reduction in permeability to water in a sand matrix containing as 1 ittle as $5 \%$ interstitial clay. (9) In this experiment, the water salinity was varied from the near saturation level to a level approaching that of distilled water. This, therefore, represented a worst case. In a 


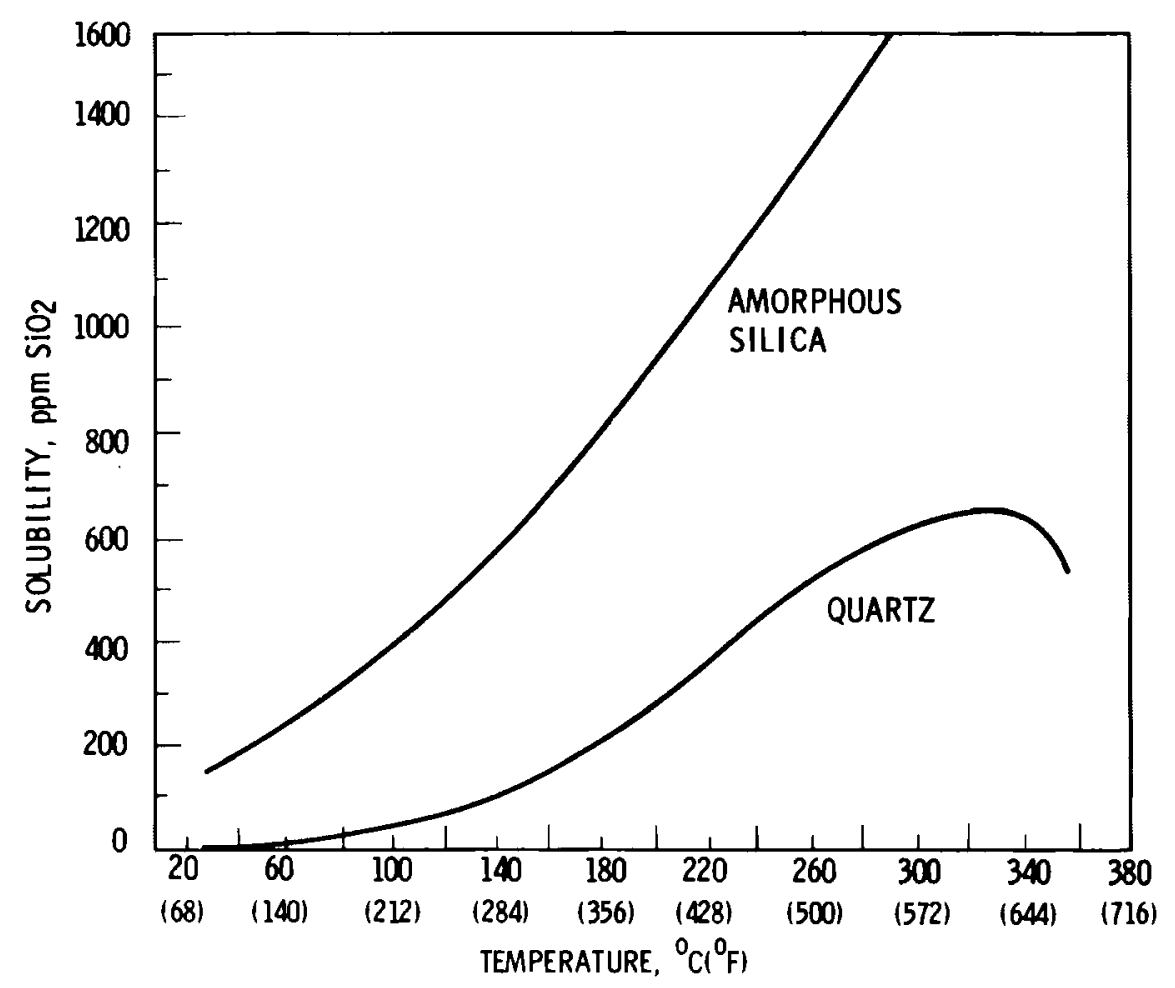

FIGURE 5-14. Silica Solubility in Water $(10)$

CAES aquifer a great deal of water will be displaced radially into the saturated zone. Also, any water vapor condensed in the storage zone will be essentially fresh water. Theoretically, this could introduce permeability reduction due to clay swell or dispersion if the smectite constituents are present. However, it must be noted that the CAES aquifer will in most cases already contain water relatively low in dissolved solids. Furthermore, the zone of condensation of fresh water should be sufficiently removed from the borehole and, therefore, a reasonable permeability reduction could be accepted without significant impact. The axially symmetric nature of the problem and the fact that the bottleneck is around the wellbore region accounts for this flexibility. Furthermore, clay swell generally tends to reduce permeability by blocking of the interstices and thus eliminating effective flow paths. It will not significantly reduce porosity because of its low occurrence percentage. In general, smectite production and/or swelling with subsequent reduction in permeability in a zone well removed from the borehole is not considered a major concern at this point. 


\subsubsection{Residual Hydrocarbons}

An obvious oxidation reaction is one that includes residual hydrocarbons. Two cases have been considered. First of a11, depleted oil fields should be considered with caution. There appears to be no effective way to flush out the residual hydrocarbons. The consequences associated with an explosion in the wellbore or in surface facilities may be sufficient to severely penalize these reservoirs in siting considerations. On the other hand, insitu combustion of the residual oil would be advantageous from the standpoint of reservoir thermal development. Furthermore, it is possible that the combustion products could be flushed from the working air zone during weekly storage cycles. Therefore, additional study is warranted before abandoned oil reservoirs are dismissed as potential CAES sites. Depleted natural gas fields should seriously be considered. It is possible to air-flush such a reservoir, and the oxidation products so generated can be effectively expelled. Monitoring of the gas/air ratio would still be recommended, however, during operation of a CAES facility.

In conclusion:

- The potential for geochemical reactions and the magnitude of the associated consequences cannot be adequately determined based on judgment and the available literature.

- The elevated temperatures and the introduction of gases, such as $0_{2}$ and $\mathrm{CO}_{2}$, to the storage matrix will result in a change of solid/liquid composition and concentration. Some new compounds may swell or may be insoluble and result in a certain degree of permeability and porosity reduction. Some reaction products in the presence of liquid phase water may result in severe corrosion problems. Finally, solids originally in solution will be deposited within the pores or in the borehole as the water is evaporated from the critical zone. Porosity and permeability degradation due to: 1) deposition of solid constituents, 2) matrix consolidation subsequent to material dissolutioning, and 
3) destruction of casing material or surface facilities by corrosive aqueous solutions must be quantified to some extent. It is clear that the critical zone must be dewatered. For the CAES concept to be viable, it must be demonstrated that one does not suffer an unacceptable penalty in the form of adverse geochemical reactions in the process.

- The reactions are strongly dependent on temperature and the presence of liquid phase water.

- The most interesting reactions are: hydrolysis and/or oxidation of silicates, carbonates, and sulfides, chloride stress corrosion, and silica and calcite scaling.

- Any siting criteria based on chemical composition of the storage zone or the caprock must be identified, i.e., cement should be silica, not calcite for elevated temperature air storage.

- The response of shale containing sulfides, carbonates and organic material should be determined.

- As potential CAES sites, depleted liquid hydrocarbon reservoirs should be considered with caution. Abandoned gas reservoirs appear attractive however.

\subsection{PHYSICAL RESPONSE OF THE POROUS ROCK}

Some attention has been given to the potential for microscopic level spalling and the subsequent production of mobile fine particles. These particulates could potentially block constrictions in the available pore space and lead to decreased porosity and effective permeability. Differential thermal expansion, deterioration of cement bonds between grains, and fragmentation of grains at sharp (high stress) grain contacts could result in collapse of the granular structure itself as well as the production of particles. Conversely, the high mass flow rates and cyclic nature of a CAES facility might clean out the matrix and improve porosity and permeability.

As a result of this concern, any laboratory efforts should address the following potential problems: 1) differential thermal expansion, 2) grain microfracturing and disintegration, and 3) dehydration of integranular cements 


\section{REFERENCES}

1. D. L. Katz and E. R. Lady, Compressed Air Storage for Electric Power Generation. Ulrichs Books, Inc., Ann Arbor, MI 48106, 1976.

2. G. P. Willhite and W. K. Dietrich, "Design Criteria for Completion of Steam Injection We1ls," Society of Petroleum Engineers, July 1967.

3. R. E. Peterson, "Fatigue of Metals: Part 3 Engineering and Design Aspects," Materials Research and Standards. P. 122, February 1963.

4. D. L. Katz et a1., Handbook of Natural Gas Engineering. McGraw-Hill Book Company, New York, NY 10001, 1959.

5. N. R. Morrow, "Irreducible Wetting-Phase Saturation in Porous Media," Chemical Engineering Science. 25:1799-1815, 1970.

6. D. L. Katz and K. H. Coats, Underground Storage of Fluids. UTrichs Books Inc., Ann Arbor, MI 48106, 1975.

7. W. H. Sommerton, J. A. Keese, and S. L. Chu, "Thermal Behavior of Unconsolidated 0il Sands," Society of Petroleum Engineers, 1974.

8. H. J. Ramey, "Wellbore Heat Transmission," Society of Petroleum Engineers, March 1962.

9. S. K. Sanyal, J. R. Marsden, and J. R. Ramey, "Effect of Temperatures on Petrophysical Properties of Reservoir Rocks," Society of Petroleum Engineers, July 1967.

10. H. L. Barnes, "Chemistry of Scale Formation," Workshop on Materials Problems Associated with Geothermal Energy Systems," Geothermal Resources Council, El Centro, CA 92243, May 1975. 


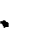




\section{BIBL IOGRAPHY}

Agarwal, R. G. et al., "The Importance of Water Influx in Gas Reservoirs." Society of Petroleum Engineers Journal. 1336-1342, 1965.

Al-Hussainy, R., H. J. Ramey, Jr., and P. B. Crawford, "The Flow of Real Gases through Porous Media." Society of Petroleum Engineers Journal. 624-636, 1965.

Anand, J., W. H. Somerton and E. Gomaa, "Predicting Thermal Conductivities of Formations from Other Known Properties." Society of Petroleum Engineers Journal, 267-273, 1973.

Apps, J. A., E. L. Madsen and R. L. Hinkins, "The Kinetics of Quartz Dissolution and Precipitation." Energy and Environment, Annual Report. LBL-5299, Lawrence Berkeley Laboratory, Berkeley, CA, p. 12-15, 1975.

Aronofsky, J. S. and J. D. Porter, "Unsteady Radial Flow of Gas Through Porous Media--Variable Viscosity and Compressibility." Journal of Applied Mechanics. 23:1288-132, 1956.

Barbish, A. B. and G. H. F. Gardner, "The Effect of Heat on Some Mechanical Properties of Igneous Rocks." Society of Petroleum Engineers of AIME. SPE-2395, 1969.

Bobek, J. E., C. C. Mattax and M. 0. Denekas, "Reservoir Rock Wettability--Its Significance and Evaluation." AIME Petroleum Translations. 213:155-160, 1958.

Burnett, P., R. Ryan and C. C. Elliott, "Estimating Gas-Water Contacts in Aquifer Gas Storage Fields Using Shut-in Wellhead Pressures." Society of Petroleum Engineers Journal. 877-883, 1967.

Calhoun, J. C., M. Lewis, Jr., and R. C. Newman, "Experiments on the Capillary Properties of Porous Solids." Journal of Petroleum Technology. 1:189-196, 1949.

Childs, E. C. and N. Collis-George, "The Permeability of Porous Materials." Royal Society of London Proceedings. 201:392-405, 1950.

Coats, K. H., "A Mathematical Model Water Movement About Bottom-Water-Drive Reservoirs." Society of Petroleum Engineers Journal. 44-52, 1961.

Colonna, J., F. Brissand and J. L. Millet, "Evolution of Capillarity and Relative Permeability Hysteresis." Society of Petroleum Engineers Journal. 28-30, 1971.

Corey, A. T., "The Interrelation Between Gas and 0il Relative Permeabilities." Producers Monthly. XIX (1):38-41, 1954.

Cornel, D. and D. L. Katz, "Flow of Gases Through Consolidated Porous Media." Industrial and Engineering Chemistry. 45 (10):2145-2150, October 1953. 
Corne11, D. and D. L. Katz, "Pressure Gradients in Natural Gas Reservoirs." Journal of Petroleum Technology. 61-70, 1952.

Cullender, M. H. and R. V. Smith, "Practical Solution of Gas-Flow Equations for Wells and Pipeline with Large Temperature Gradients." Petroleum Branch. 207:281-287, 1956.

Davidson, L. B., "The Effect of Temperature on the Permeability Ratio of Different Fluid Pairs in Two-Phase Systems." Journal of Petroleum Technology. 21:1037-1046, 1969.

Day, J. J., B. B. McGlothl in and J. L. Huitt, "Laboratory Study of Rock Softening and Means of Prevention During Steam of Hot Water Injection." Society of Petroleum Engineers Journal. 703-711, 1966.

Delclaud, J. P., "New Results on the Displacement of a Fluid by Another in a Porous Medium." Society of Petroleum Engineers of AIME. SPE-4103, 1972.

deWitte, L., "Relations Between Resistivities and Fluid Contents of Porous Rocks." Journally Speaking. 83-132, August 24, 1950.

Dobrynin, V. M., "Effect of Overburden Pressure on Some Properties of Sandstones." Society of Petroleum Engineers Journa1. 360-366, 1962.

Downie, J. and F. E. Crane, "Effect of Viscosity on Relative Permeability." Society of Petroleum Engineers Journal. 59-60, September 1960.

Dranchuk, P. M. and J. Flores, "Non-Darcy Transient Radial Gas Flow Through Porous Media." Society of Petroleum Engineers Journal. 129-139, 1973.

Edmondson, T. A., "Effect of Temperature on Waterflooding." Petroleum Society of CIM. Journal of Canadian Petroleum. 236-242, May 5, 1965.

Evrenos, A. I. and A. G. Comer, "Numerical Simulation of Hysteretic Flow in Porous Media." Society of Petroleum Engineers of AIME. SPE-2693, 1969.

Evrenos, A. I. and A. G. Comer, "Sensitivity Studies of Gas-Water Relative Permeability and Capillarity in Reservoir Modeling." Society of Petroleum Engineers of AIME. SPE-2668, 1969.

Glass, E. D. and R. C. Hessing, "A Method for Computing Pressure Behavior and Volume of Gas-Storage Reservoirs." Society of Petroleum Engineers Journal. $544-548,1961$.

Gring, L. M. and B. H. Caudle, "A Visual Study of Waterflooding a Microlayered Sandstone." Society of Petroleum Engineers of AIME. SPE-4106, 1972. 
Headley, W. H., F. J. Lavacot, S. L. Wang and W. P. Armstrong, "Accessibility of Surface to Gases Diffusing Inside Macroporous Media." Association of

International Chemical Engineers. 12 (2):321-327, 1965.

Hewitt, C. H., "Analytical Techniques for Recognizing Water Sensitive Reservoir Rocks." Society of Petroleum Engineers Journal. 813-818, 1963.

Hill, H. J. and J. D. Milburn, "Effect of Clay and Water Salinity on Electrochemical Behavior of Reservoir Rocks." Journal of Petroleum Technology.

207:65-72, 1955.

Holmes, M., K. D. Dreher and A. J. Eloy, "Lithology and Fluid Properties and Their Relations to the Distribution of Saturating Fluids in Sandstone." Society of Petroleum Engineers of AIME. SPE-3554.

Hurst, W., "Establishment of the Skin Effect and its Impediment to Fluid Flow into a We1lbore." The Petroleum Engineer. 25:B-6 to B-13, 1953.

Knapp, R. M. et a1., "Calculation of Gas Recovery Upon U1 timate Depletion of Aquifer Storage." Society of Petroleum Engineers Journal 1129-1132, 1967.

Krech, W. W. and P. G. Chamberlain, "New Techniques for Measuring Rock Fracture Energy." Society of Petroleum Engineers Journal. 237-242, 1972.

Lesem, L. B., F. Greytok, F. Marotta and J. C. McKetta, "A Method of Calculating the Distribution of Temperature in Flowing Gas Wells." Society of Petroleum Engineers Journal. 210:169-176, 1956.

Lo, H. Y. and N. Mungan, "Effect of Temperature on Water-0il Relative Permeabilities in 0il-Wet and Water-Wet Systems." Society of Petroleum Engineers of AIME. SPE-4505

Morgan, J. T. and D. T. Gordon, "Influence of Pore Geometry on Water-0i1 Relative Permeability" Journal of Petroleum Technology. 22:1199-1208, 1970.

Morrow, N. R. and C. C. Harris, "Capillary Equilibrium in Porous Materials." Society of Petroleum Engineers Journal. 15-24, 1964.

Mungan, Necmettin, "Interfacial Effects in Immiscible Liquid-Liquid Displacement in Porous Media." Society of Petroleum Engineers Journal. 247-253, 1966.

ODeh, A. S., "Effect of Viscosity Ration on Relative Permeability." Journal of Petroleum Technology. 216:346-353, 1959.

Powers, E. L. and H. G. Botset, "Note on the Relation Between Capillary Pressure and Interfacial Tension." Producers Monthly. XII (8):15-18, June 1949.

Preston, D. A., "Correlation of Certain Physical and Chemical Properties in Sedimentary Rocks." Shel1 Oil Company, Houston, TX. 
Purce11, W. R., "Capillary Pressures--Their Measurement Using Mercury and the Calculation of Permeability Therefrom." Journal of Petroleum Technology. 1:39-48, 1949

Ramey, H. J., "Wellbore Heat Transmission." Society of Petroleum Engineers Journal. 427-435, 1961.

Rapoport, L. A. and W. J. Leas, "Relative Permeability to Liquid in Liquid-Gas Systems." Journal of Petroleum Technology. 192:83-98, 1951.

Sanyal, S. K., S. S. Marsden and H. J. Ramey, "Effect of Temperature on Petrophysical Properties of Reservoir Rocks." Society of Petroleum Engineers of AIME. SPE-4898, 1974.

Singh, M. M. and P. J. Huck, "Effect of Specimen Size on Rock Properties." Society of Petroleum Engineers of AIME. SPE-3528, 1971.

Sinnokrot, A. A., H. J. Ramey and S. S. Marsden, "Effect of Temperature Level Upon Capillary Pressure Curves." Society of Petroleum Engineers Journal. II (1):13-22, March 1971.

Smith, R. V., "Unsteady-State Gas Flow into Gas Wells." Society of Petroleum Engineers Journal. 1151-1159, 1960.

Somerton, W. H. and V. S. Gupta, "Role of Fluxing Agents in Thermal Alteration of Sandstones." Journal of Petroleum Technology. 585-588, May 1965.

Somerton, W. H. and G. D. Boozer, "Thermal Characteristics of Porous Rocks at Elevated Temperatures." Society of Petroleum Engineers Journal. 77-81, August 24, 1959.

Somerton, W. H., M. M. Mehta and G. W. Dean, "Thermal Alteration of Sandstones." Journal of Petroleum Technology. 589-593, May 1965.

Stone, H. L., "Estimation of Three-Phase Relative Permeability and Residual

$0 i 1$ Data." The Journal of Canadian Petroleum Technology. 12 (4):53-60, October-December 1973.

Tek, M. R., K. H. Coats and D. L. Katz, "The Effect of Turbulence on Flow of Natural Gas Through Porous Reservoirs." Society of Petroleum Engineers Journal. 799-806, 1961.

Treiber, L. E., D. L. Archer and W. W. Owens, "A Laboratory Evaluation of the Wettability of Fifty 0il-Producing Reservoirs." Society of Petroleum Engineers Journal. 531-540, 1971.

van Brakel, J. and P. M. Heertjes, "Analysis of Diffusion in Macroporous Media in Terms of a Porosity, a Tortuosity and a Constrictivity Factor. "International Journal of Heat Mass Transfer. 17:1093-1103, 1973. 
VanEverdingen, A. F., "The Skin Effect and its Influence on the Productive Capacity of a We11." Journal of Petroleum Technology. 198:171-176, 1953.

Von Gonten, W. D. and B. K. Choudhary, "The Effect of Pressure and Temperature on Pore Volume Compressibility." Society of Petroleum Engineers of AIME. SPE-2526, 1969.

Wa11, C. G., "Permeability: Pore Size Distribution Correlations." Institute of Petroleum Journal. 51 (498):195-200, June 1965.

Walsh, J. B. and E. R. Decker, "Effect of Pressure and Saturating Fluid on the Thermal Conductivity of Compact Rock." Journal of Geophysical Research. 71 (12):3053-3061, 1966.

Walsh, J. B. and E. R. Decker, "Effect of Pressure and Saturating Fluid on the Thermal Conductivity of Compact Rock." Journal of Geophysical Research. 71(12):3053-3061, 1966.

Weinbrandt, R. M., H. J. Ramey and F. J. Cassé, "The Effect of Temperature on Relative and Absolute Permeability of Sandstones." Society of Petroleum Engineers Journal. 376-383, 1972.

Willhite, G. P., "Over-all Heat Transfer Coefficients in Steam and Hot Water Injection Wells." Society of Petroleum Engineers Journal. 607-615, 1966.

Willhite, G. P. and W. K. Dietrich, "Design Criteria for Completion of Steam Injection Wells." Society of Petroleum Engineers Journal. 15-21, 1966.

Winsauer, W. 0. and W. M. McCarde11, "Ionic Double-Layer Conductivity in Reservoir Rock." Journal of Petroleum Technology. 6:129-134, 1953.

Witherspoon, P. A. and S. P. Neuman, "Evaluating a Slightly Permeable Caprock in Aquifer Gas Storage: I. Caprock of Infinite Thickness." Society of Petroleum Engineers Journal. 949-955, 1966.

Zen, E-An, "Clay Mineral-Carbonate Relations in Sedimentary Rocks." American Journal of Science. 257:29-43, 1959. 


\section{DISTRIBUTION}

No. of

Copies

OFFSITE

A. A. Churm

DOE Chicago Patent Group

Chicago Operations Office

9800 South Cass Avenue

Argonne, IL 60439

3 G. C. Chang

DOE Division of Energy Storage Systems

Advanced Physical Methods

Branch

Washington, DC 20545

27 DOE Technical Information Center

J. S. Edmonds

Division of Electric Energy Systems

U.S. Department of Energy

Washington, DC 20545

Chief, APMBR

Division of Energy Storage Systems

U.S. Department of Energy Washington, DC 20545

R. Derby

Division of Energy Storage Systems

U.S. Department of Energy

Washington, DC 20545

Director

Division of Energy Storage Systems

U. S. Department of Energy Washington, DC 20545
No. of

Copies

J. H. Swisher

Division of Energy Storage Systems

U.S. Department of Energy

Washington, DC 20545

D. W. Boehm

Division of Environmental

Control Technology

U.S. Department of Energy

Washington, DC 20545

Assistant Director for Major Projects

Division of Solar Energy

U.S. Department of Energy

Washington, DC 20545

Assistant Director for Thermal

Power Systems

Division of Solar Energy

U.S. Department of Energy

Washington, DC 20545

DOE Library

U.S. Department of Energy

Mail Station G-043

Washington, DC 20545

R. F. Kimberlin

DOE Library

U.S. Department of Energy

Room 1223

Washington, DC 20545

D. Willett

Acres American, Inc.

Liberty Bank Building

Main at Court

Buffalo, NY 14202 
No. of

Copies

American Public Power Association

2600 Virginia Avenue, NW

Washington, DC 20037

2 G. T. Kartsounes

Argonne National Laboratory

9700 South Cass Avenue

Argonne, IL 60439

Manager, Research and

Development

Bonneville Power Administration

P.0. Box 3621

Portland, OR 97208

Research Library, Reference Section

Information Division

Brookhaven National

Laboratory

Upton, NY 11973

Vice President, America

Brown Boveri Corporation

New Brunswick, NJ 08902

Director of Research

Cincinnati Gas and

Electric Company

139 East Fourth Street

Cincinnati, OH 45202

D. E. DeViney

Commonwealth Edison Company

1319 South First Avenue

Maywood, IL 60153

R. A. Bell

Consolidated Edison Company

4 Irving Place

New York, NY 10003
No. of

Copies

T. Schneider

Electric Power Research Institute

Box 10412

Palo Alto, CA 94303

D. Anderson

Fenix and Scisson, Inc.

P.0. Box 15609

Tulsa, OK 74115

Director of Research GPU Service Corporation

260 Cherry Hill Road

Parsippany, NJ 07054

A. H. Barber

Director of Marketing

Harza Engineering Company

150 S. Wacker Drive

Chicago, IL 60606

Library

Lawrence Berkeley Laboratory

University of California

Bldg. 50, Room 134

Berkeley, CA 94720

3 Technical Information

Department, $L-3$

Lawrence Livermore Laboratory

University of California

P.0. Box 808

Livermore, CA 94550

Director of Research

Louisiana Power and Light

142 Delaronde Street

New Orleans, LA 70174

I. Glendenning

Head of Long-Term Studies

Marchwood Enginnering Labs

Southampton, England 
No. of

Copies

L. A. Wilson

Middle South Services

P.0. Box 61000

New Orleans, LA 70161

G. T. Flynn

Energy Systems Engineer

MIT/Lincoln Laboratory

Lexington, MA 02173

J. E. Calogeras

NASA Lewis Research Center

21000 Brookpark Road

Cleveland, $\mathrm{OH} 44135$

Division of Advanced Energy

Research and Technology

National Science Foundation

Room 1140

1800 G Street, NW

Washington, DC 20550

C. G. Nelson

Manager, Storage Operations

Northern Illinois Gas Company

P.0. Box 190

Aurora, IL 60507

P. E. Schaub

Potomac Electric Power Company

1900 Pennsylvania Avenue

Washington, DC 20006

T. McCafferty

Public Service Company of Indiana

1000 E. Main Street

Plainfield, IN 46168

2 Technical Library

Department 3141

Sandia Laboratory

Albuquerque, NM 87115
No. of

Copies

S. Serato

Serato Geomechanics, Inc.

1229 Eighth Street

Berkeley, CA 94710

Energy Research Section

Tennessee Valley Authority

1360 Commerce Union Bank B1dg.

Chattanooga, TN 37401

0 . Manaker

Director of Research

Tennessee Valley Authority

Chattanooga, TN 37401

E. Berman

Technical Library

TRW Energy Systems Group

7600 Colshire Drive

McLean, VA 22101

E. H. King

Underground Design Consultants

820 Cascade Bldg.

Portland, OR 97204

A. I. Giramonti

United Technologies Research Center

Silver Lane

East Hartford, CT 06108

3 H. J. Pincus

University of Wisconsin

Department of Geological Sciences

Sabin Hall and Greene Museum

P.0. Box 413

Milwaukee, WI 53201

D. Ayers

Manager, Fluid Systems

Laboratory

Westinghouse Electric

Corporation

1291 Cumberland Avenue

West Lafayett, IL 47906 
No. of

Copies

ONSITE

DOE Richland Operations

Office

H. E. Ransom

Battelle-Northwest

H. J. Bomelburg

D. B. Cearlock

T. J. Doherty

J. R. Eliason

L. L. Eyler

J. R. Friley

A. J. Haverfield

D. K. Kreid (3)

W. V. Loscutoff (10)

M. A. Mckinnon (3)

C. A. Oster

L. T. Pederson

S. J. Phillips

J. W. Shupe

G. C. Smith (3)

R. P. Smith

J. A. Stottlemyre (3)

A. M. Sutey

D. S. Trent

L. E. Wiles (3)

Technical Information (5)

Publishing Coordination (2) 